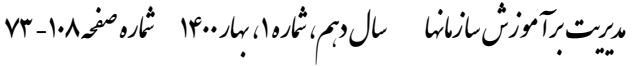

\section{نقثى عدالت سازمانى در رضايت شغلى \\ با ميانجى}

*محمدرضا اردلان، دانشيار مديريت آموزشى، گروه علوم تربيتى، دانشكده علوم انسانى، دانشًاه بوعلى سينا، همدان، ايران.

حسين معجحونى، دانشجوى دكترى مديريت آموزشى، گروه علوم تربيتى، دانشكده علوم انسانى، دانشگاه بوعلى سينا، همدان، ايران.

جكيده

هدف يروهش حاضر بررسى نقش عدالت سازمانى در رضايت شغلى با ميانجى

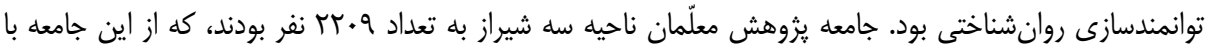

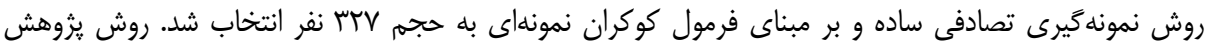

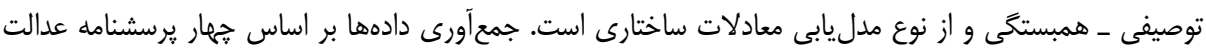

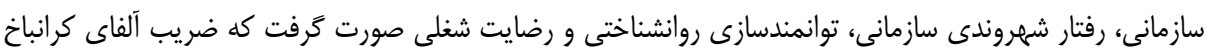

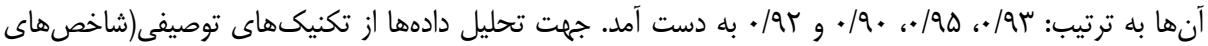

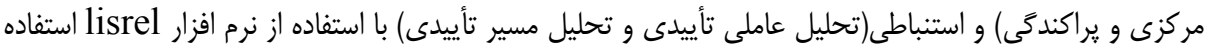

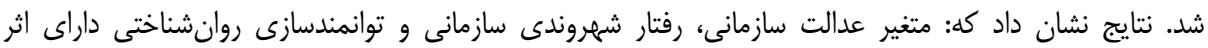

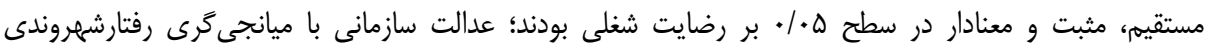

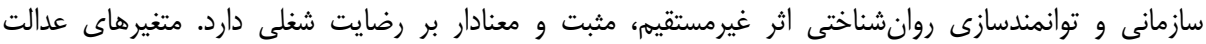

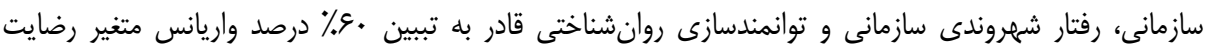
شغلى مىباشند.

وازَّان كليدى : عدالت سازمانى، رفتار شهروندى سازمانى، توانمندسازى روانشناختى، رضايت شغلى، معلّمان

ardalanmr@yahoo.com : نويسنده مسئول: *

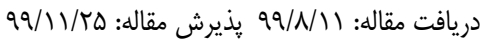




\title{
The Role of Organizational Justice in Job Satisfaction by Mediating Organizational Citizenship Behavior and Psychological Empowerment
}

\author{
*Mohammad Reza Ardalan, Associate Professor of Educational \\ Management, Department of Educational Sciences, Faculty of Humanities, Bu Ali \\ Sina University, Hamadan, Iran. \\ Hosein Majooni, PhD Student of Educational Management, Department of \\ Educational Sciences, Faculty of Humanities, Bu Ali Sina University, Hamadan, Iran.
}

\begin{abstract}
The purpose of this study was to investigate the role of organizational justice in job satisfaction by mediating organizational citizenship behavior and psychological empowerment. The study population consisted of 2209 teachers in the district of Shiraz, selected by simple random sampling and based on Cochran formula with a sample size of 327. The research method is descriptive-correlational and especially structural equation modeling. Data collection based on four organizational justice questionnaires, Organizational Citizenship Behavior, The psychological empowerment and the job satisfaction were performed with Cronbach's alpha coefficient of $0.93,0.95,0.90$ and 0.92 , respectively. The results indicated the optimal reliability and validity of the tool. Descriptive (central and dispersion indices) and inferential (confirmatory factor analysis and confirmatory path analysis) techniques were used for data analysis using lisrel software. For descriptive data analysis techniques (central and dispersion parameters) and inferential statistics (confirmatory factor analysis, path analysis confirmed) lisrel were using the software. The results showed that the variables of organizational justice, organizational citizenship behavior, and psychological empowerment had a direct, positive and significant effect on job satisfaction at the 0.05 level; organizational justice mediated organizational citizenship behavior and psychological empowerment had an indirect, positive and significant effect on job satisfaction. The variables of organizational justice, organizational citizenship behavior, and psychological empowerment are able to explain $60 \%$ of the variance of job satisfaction.
\end{abstract}

Keywords: Organizational Justice, Organizational Citizenship Behavior, Psychological Empowerment, Job Satisfaction, Teachers.

* Corresponding author: ardalanmr@yahoo.com

Receiving Date: 1/11/2020 Acceptance Date: 13/2/2021 
امروزه تمامى صاحبنظران و انديشمندان بر اهميّت و نقش نيروى انسانى به عنوان عامل توسعه در هر كشور واقفند (Mohseni \& Mirgol, 2019, P. 2) و بر اين نكته تأكيد دارند كه ونه

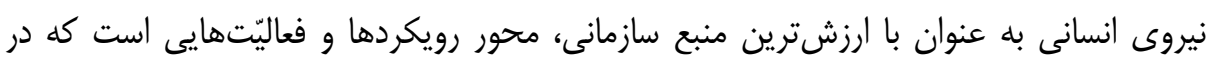

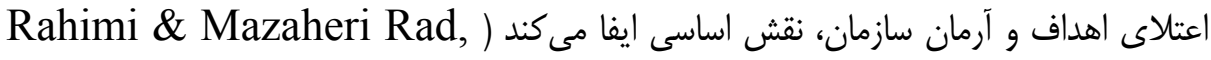
2017, P. 37 PahlavanSadegh \& Abdollahi, ) رهخذر هدف سازمانهاى موفّق را فراهم نمايد مئل (2015, P. 88

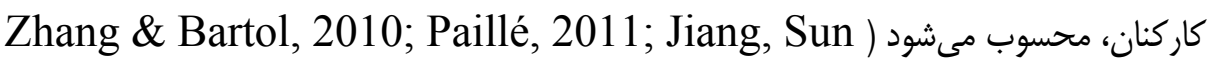
(\& Law, 2011 Tى تعهّد و علاقهى آنان به سازمان مىباشد ) و \& Florescu, 2015; Hosie \& et al, 2013

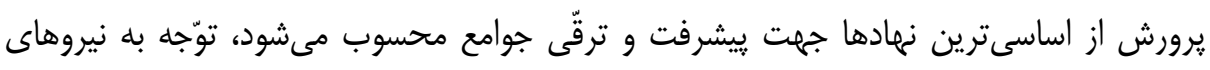

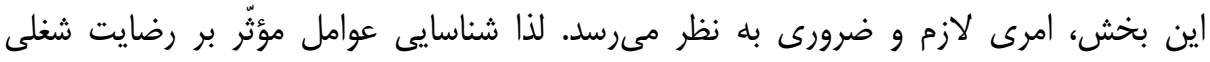

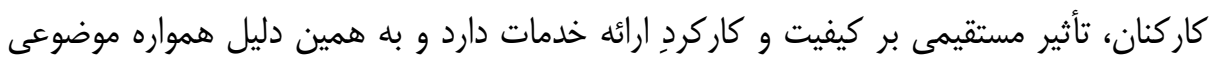
حياتى و مهم براى بررسى بوده است (Salimi \& Abdi, 2018). از جمله عوامل تأثيركذار بر رضايتشغلى، توانمندسازى روانشناختى كاركنان بـ مىباشد.

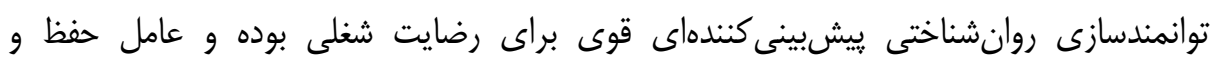

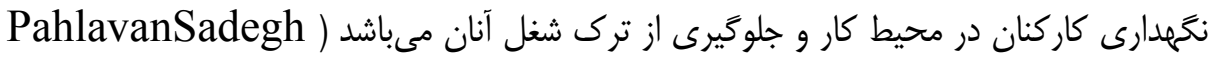
\& Abdollahi, 2015, P. 89

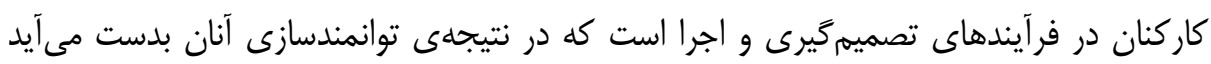

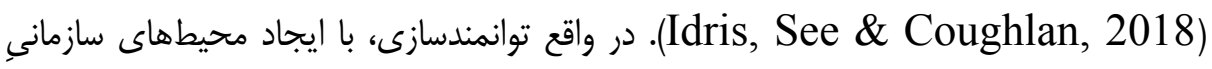

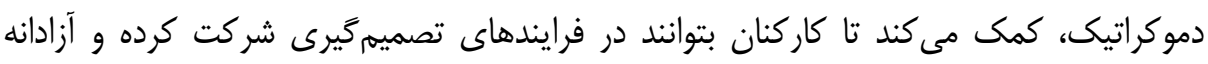

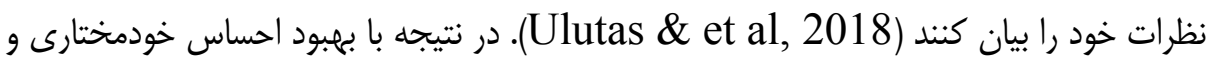

1. Job Satisfaction

2. Psychological Empowerment of Employees 
Lee, Kim \& Kim, ) ييشرفت كاركنان در محل كار، رضايت شغلى آنان افزايش ييدا مى كند

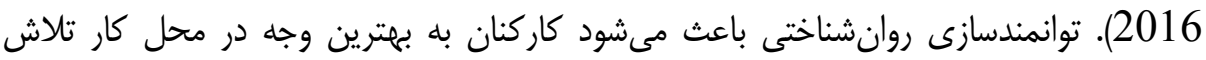

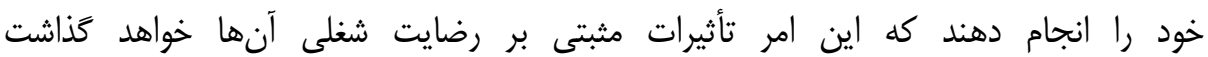

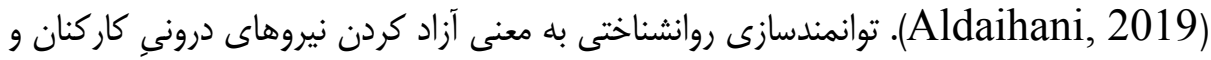

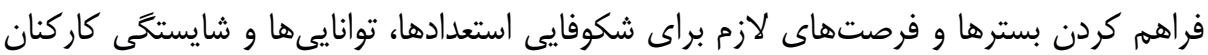

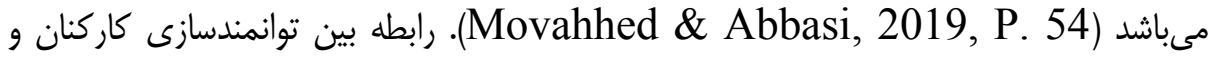

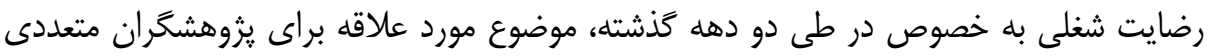

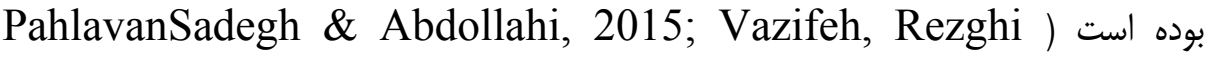
Rostami \& Pakdel, 2019; Seibert, Silver \& Randolph, 2004; Pelit, Öztürk \& Arslantürk, 2011; Ölçer \& Florescu, 2015; Carless, 2004). برخى از كاركنان نسبت به سايرين بيشتر يذيراى توانمندسازى هستند ( El-Kot,

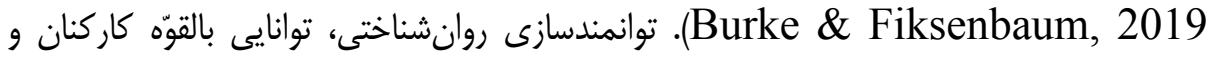

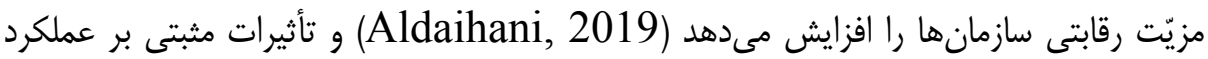
كلّى سازمانها مى خذارد (Dabo, \& Ndan, 2018).

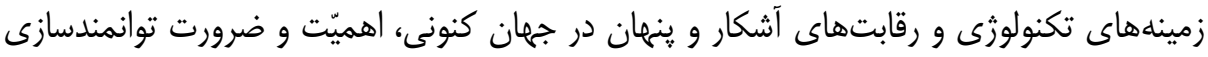

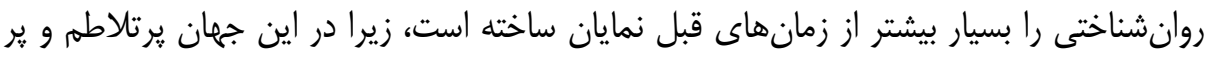

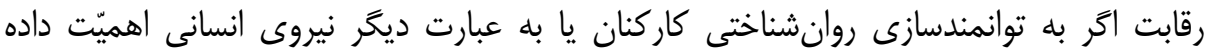

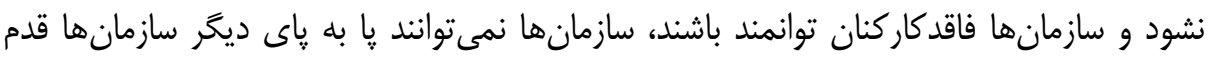

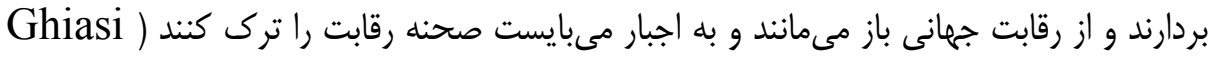

(Nadishan, Jahani Javanmardi \& Khorsandi taskoh, 2017, P. 79

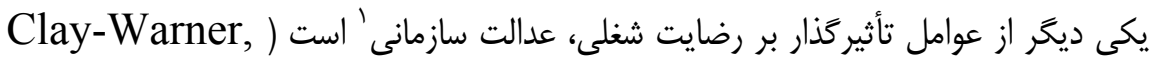

تأثر كلار د. 392

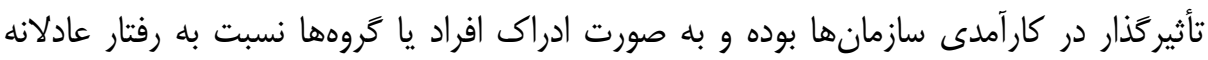

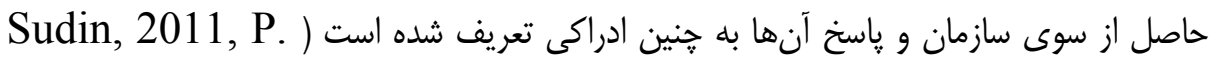

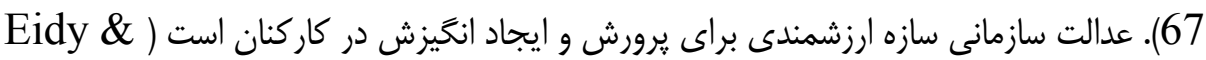

1. Organizational Justice 
(et al, 2018, P. 191

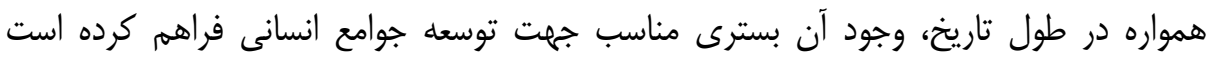
(Nazari, R., \& Rafei, 2018, P. 42)

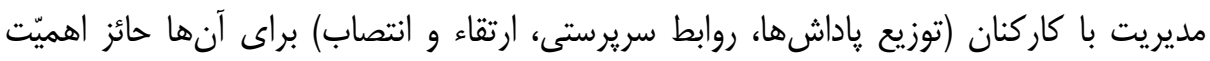

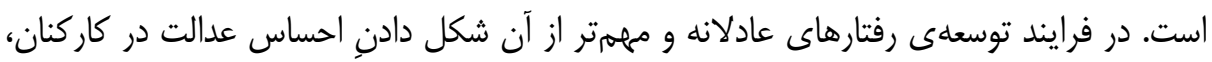

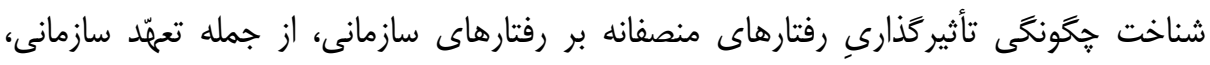

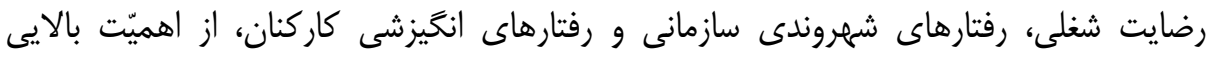

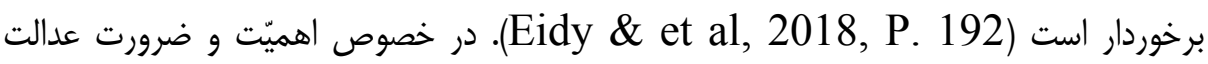

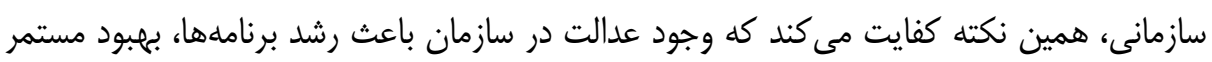

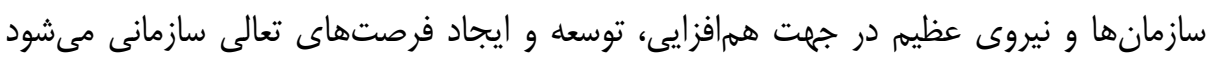
(Pourseltani Mirzaei \& Zareian, 2012, P. 61 )

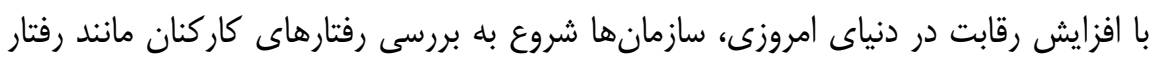

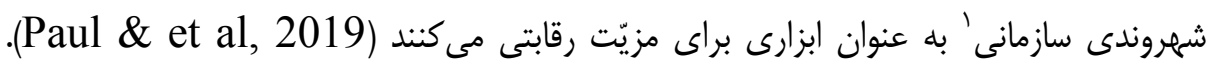

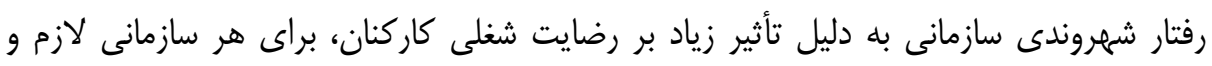

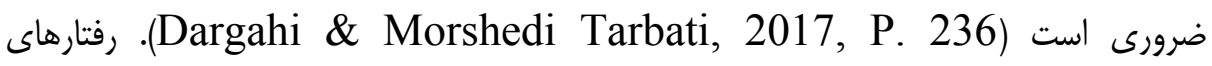

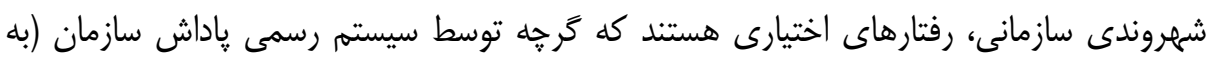

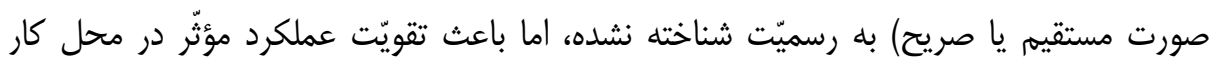

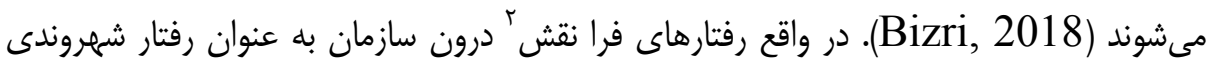

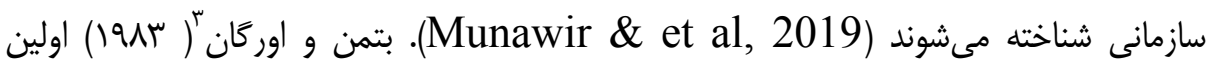

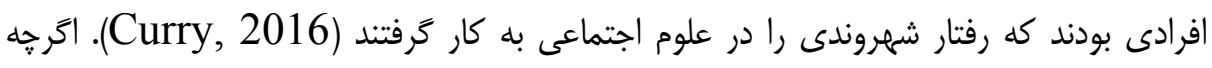

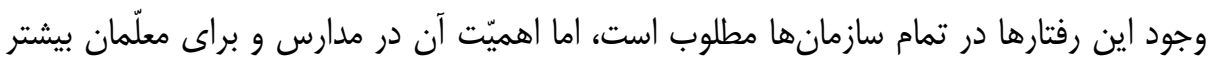

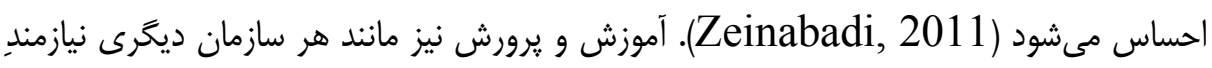

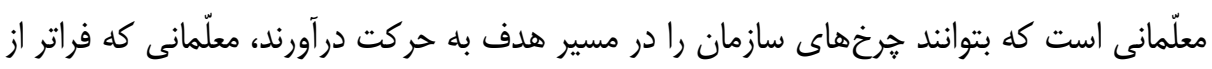

1. Organizational Citizenship Behavior

2. Meta-role behaviors

3. Bateman TS, Organ DW 
شرح شغل خود تلاش كنند و سازمان را موطن خود بدانند، خرا كه رفتارهاى شهروند سازماني

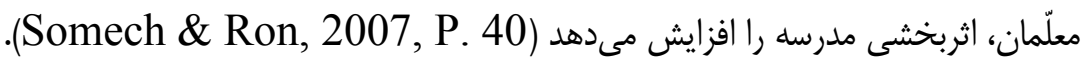

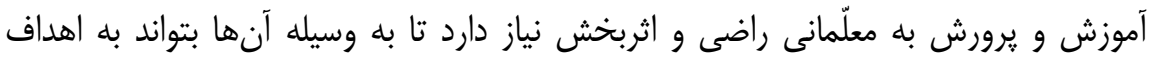

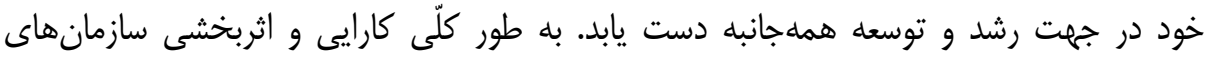

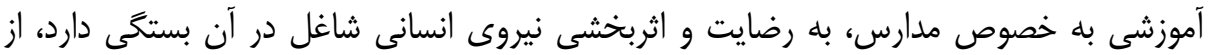

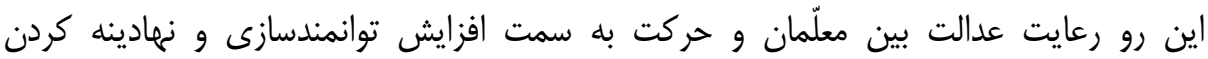

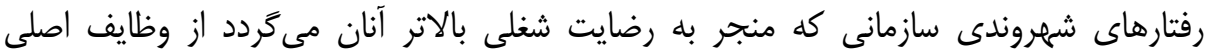

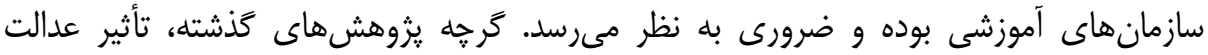

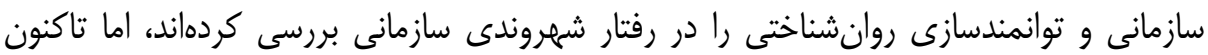

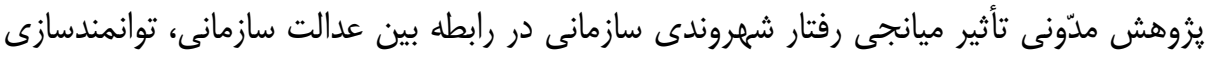

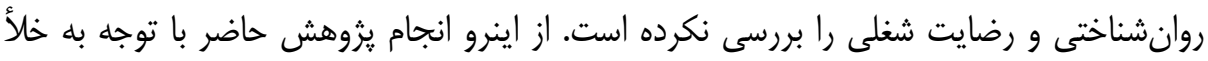

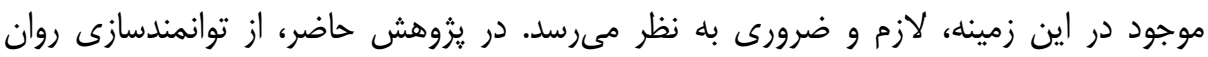
شناختى و رفتار شهروندى سازمانى به عنوان متغيّرهاى ميانجى استفاده كردهايم تا تأثير تعديل

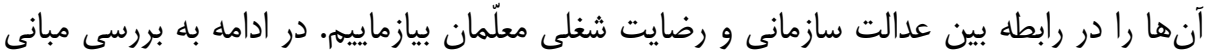

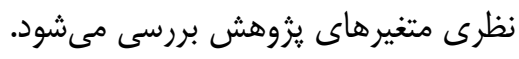

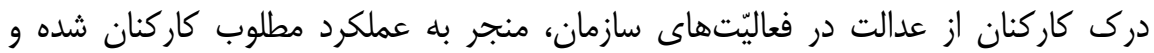

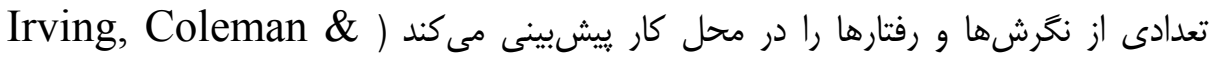

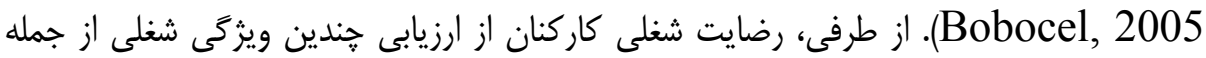

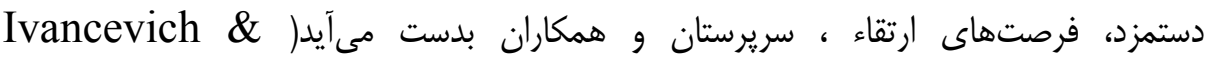
Skarlicki \& Folger(2003). (Matteson, 2005, p. 101

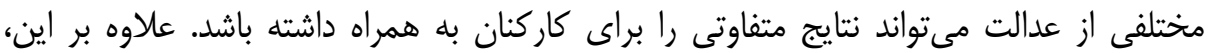

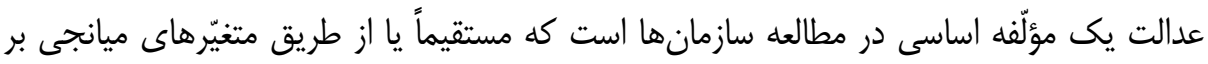

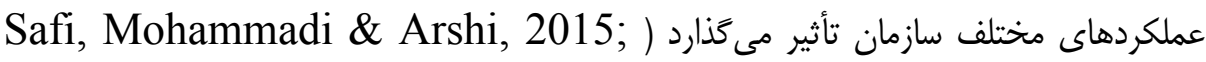
Nadi \& Esmaeili Harandi, 2017; Nazari \& Rafei, 2018; Gholampour \& Pourshafei, 2018; Mohseni \& Mirgol, 2019; Nazir \& et al, 2019; Kundu \& et al, 2019; Oh, 2019; Arab \& Atan, 2018). عدالت سازمانى به عنوان يك رشته يزوهشى، بيشترين مطالعات را در حوزهى دانش به

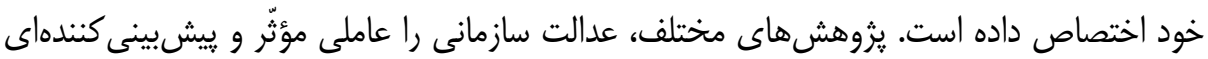


Nadi \& Esmaeili Harandi, ) قوى براى رضايت شغلى كاركنان در نظر كرفتهاند 2017; Gholampour \& Pourshafei, 2018; Nazari \& Rafei, 2018; Colquitt \& et al, 2001; Madera, Dawson \& Guchait, 2016: Singhry, 2018; Suifan, Diab \& Abdallah, 2017 مطالعات Hao, Hao \& Wang(2016) نشان داد كه عدالت توزيعى، رويّهاى و تعاملى رابلى

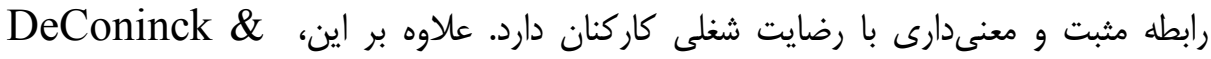

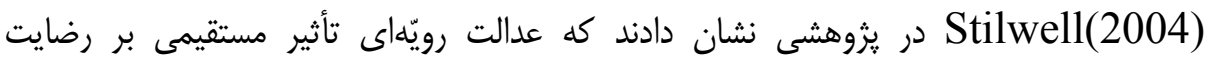

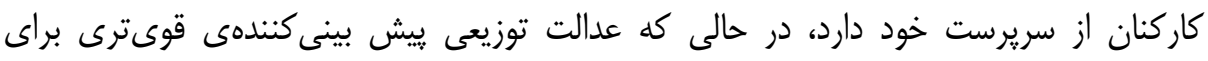

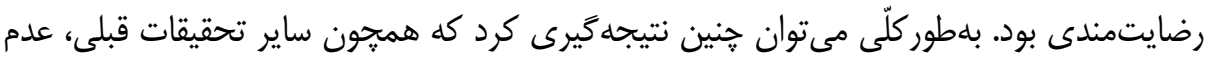

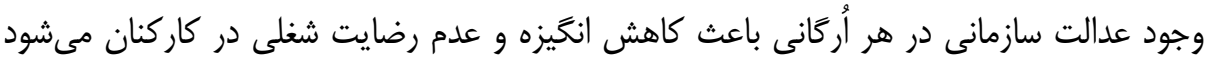
.(Nazari, R., \& Rafei, 2018)

رفتار شهروندى سازمانى نوعى از رفتارهاى اختيارى كاركنان است كه با حفظ و تقويّيت

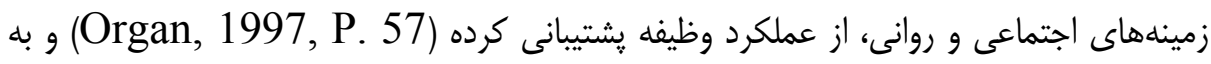

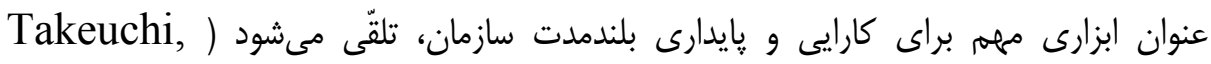

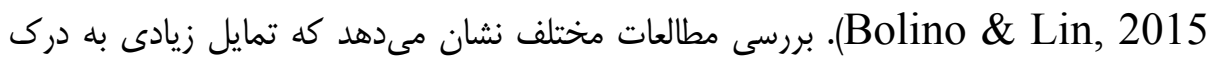

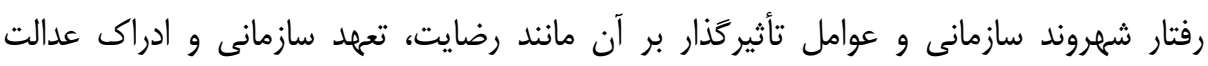

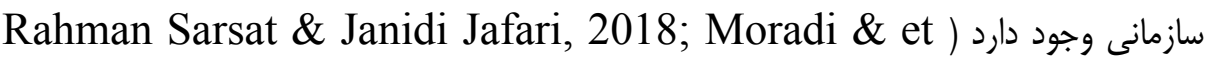
al, 2019; Takeuchi, Bolino \& Lin, 2015; Gupta \& Singh, 2013; Gao \& He, 2017; Chan \& Lai, 2017; Ahmad \& et al, 2019

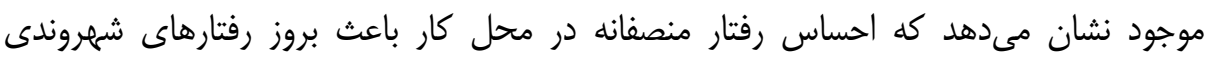

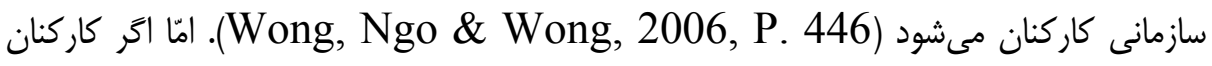

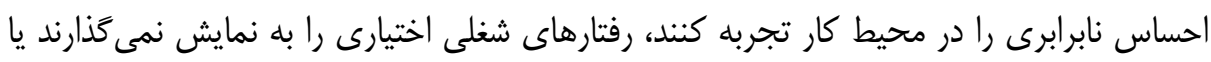

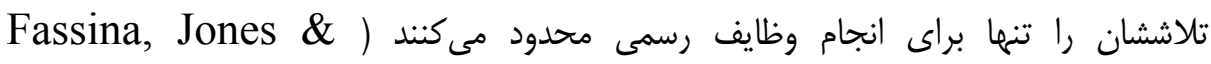

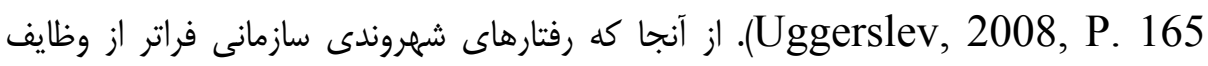

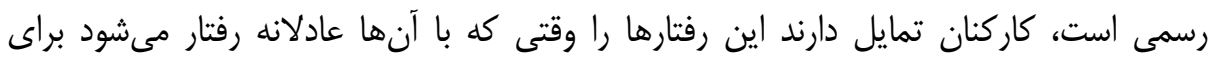

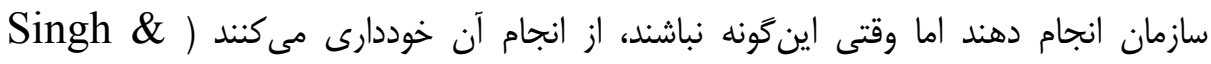
(Singh, 2019 
توانمندى منابع انسانى به عنوان يك رويكرد نوين انغيزش درونى شرون شغل، به معنى آزاد كردن

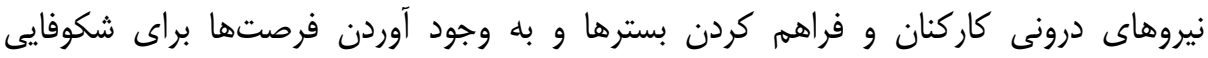

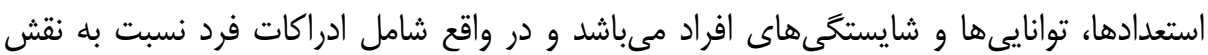

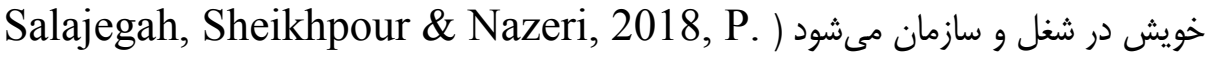

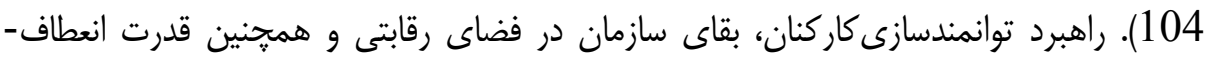

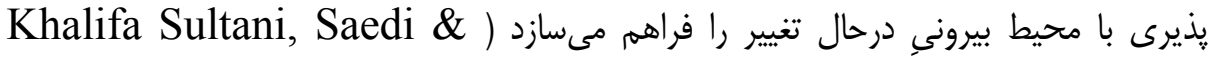

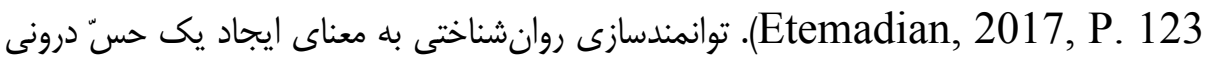

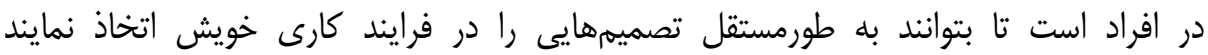
(Kordnaij, Bakhshi Zadeh \& Fatah Elahi, 2015, P. 99) متغيّرهايى كه باعث افزايش توانمندى روانشناختى كاركنان مىشود، ادارك آنان از رعايت عدالت

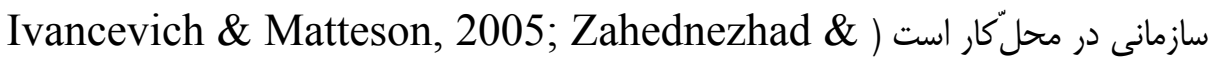
et al, 2015; Eidy \& et al, 2018; Franz, 2004; Li \& et al, 2016; توانئساري 2017 (Muqadas, Rehman \& Aslam, عدالت ادراك شده در سازمان به رشد :

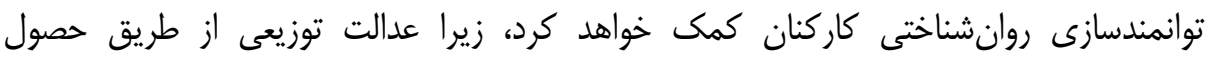

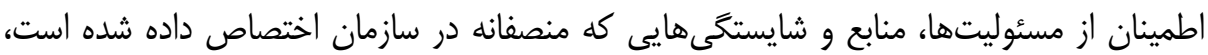

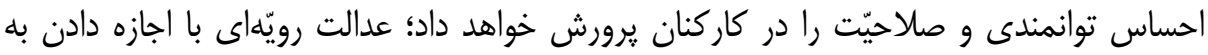

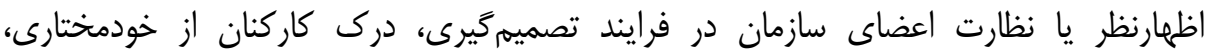

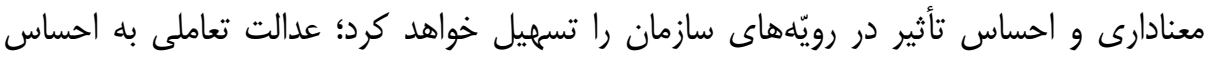

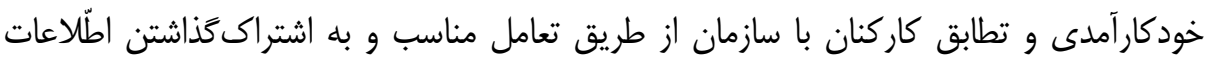

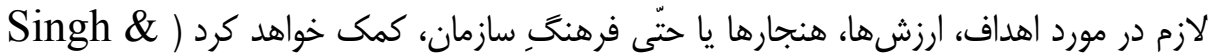

.(Singh, 2019

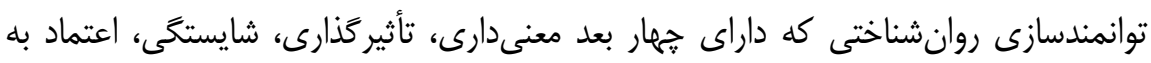

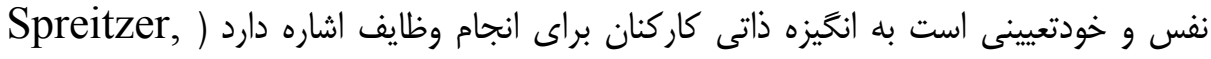

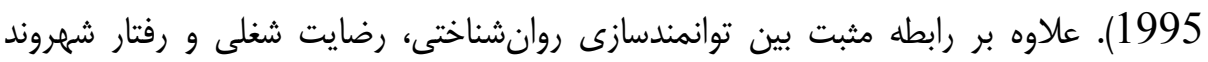

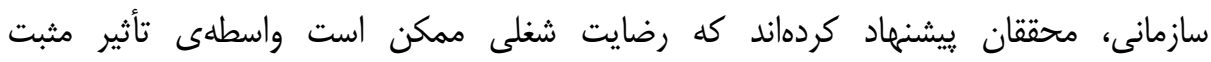

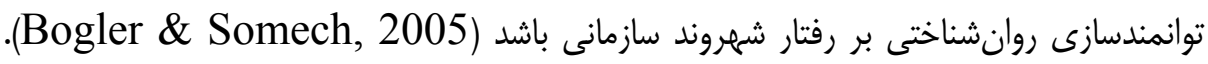

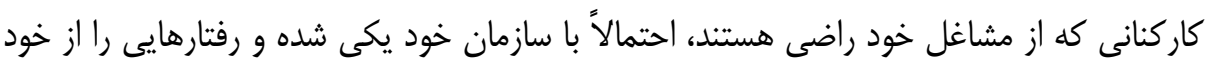


بروز مىدهند كه كرجها بطور مستقيم تشخيص داده نمىشود، امّا براى سازمان مفيد است.

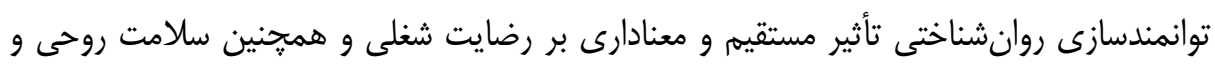

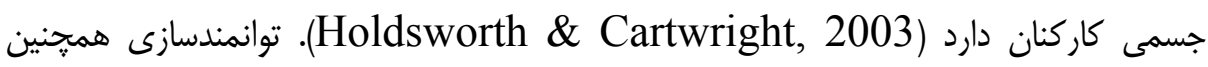

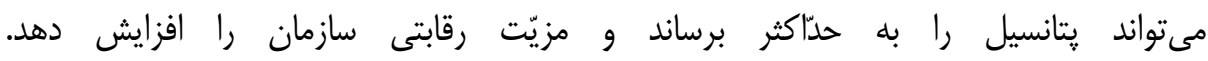

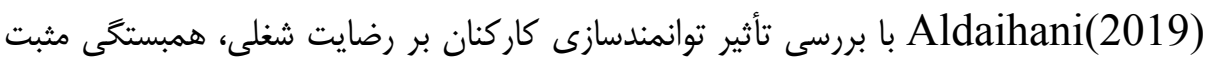

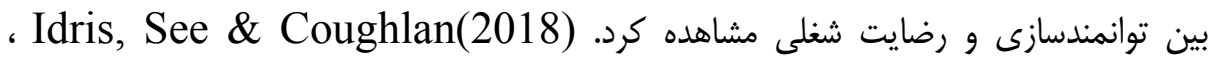
ليز در Jamshidian(2017) و Vazifeh, Rezghi Rostami \& Pakdel(2019)

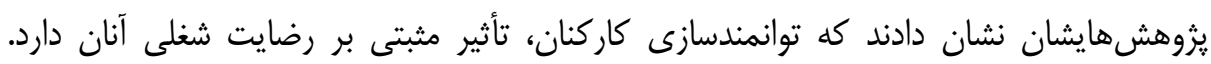

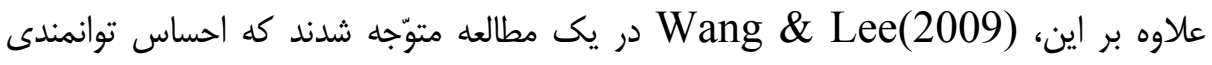

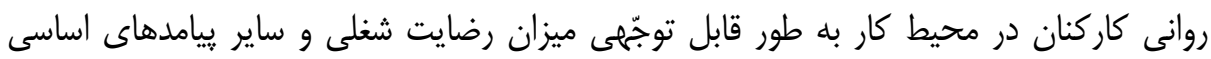

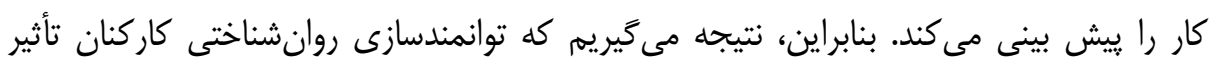

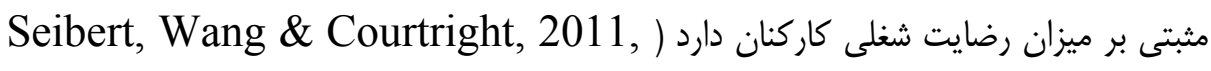

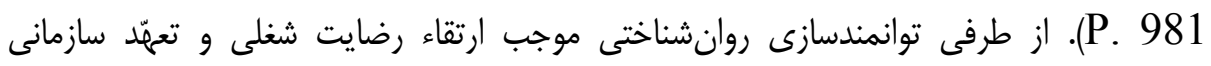

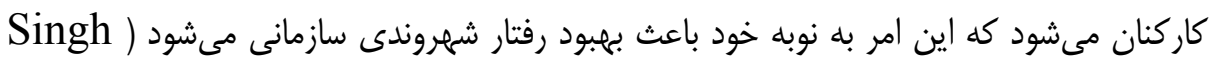
. \& Singh, 2019

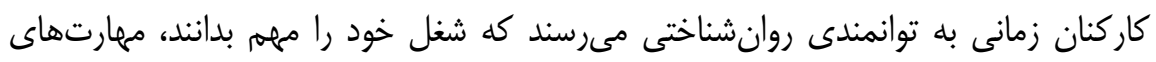

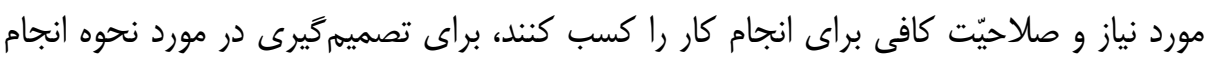

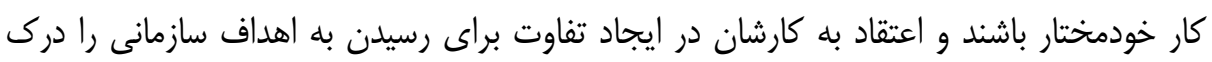

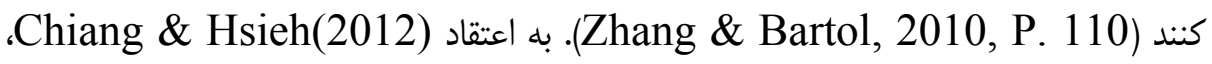

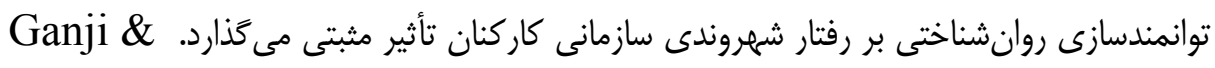
karimi baghmalek(2018)

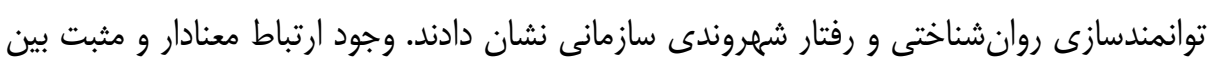

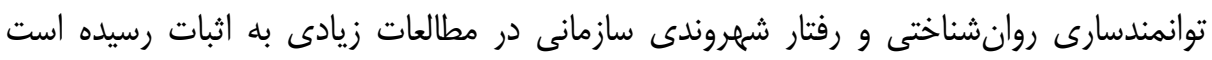
Mohammadkhani \& et al, 2013; Aghajan \& et al, 2013; Safari \& ) et al, 2016; Salimi \& Abdi, 2018; Gilbert \& et al, 2010; Arefin, Arif \& Raquib, 2015; Ioannidou \& et al, 2016; Newman \& et al, 2017). كاركنان توانمند، سطح بالايى از مشاركت و ابتكارعمل در شناسايى موضوعات و ارائه 


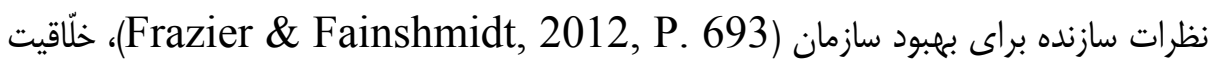

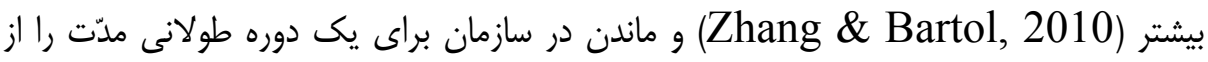

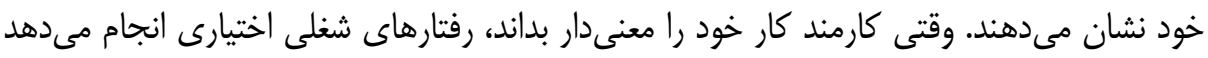

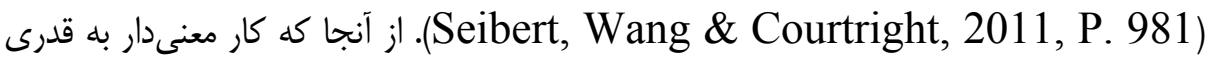

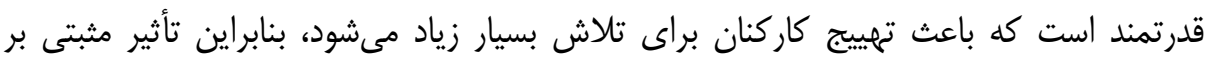

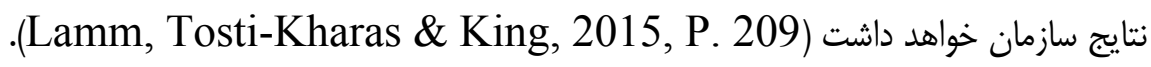

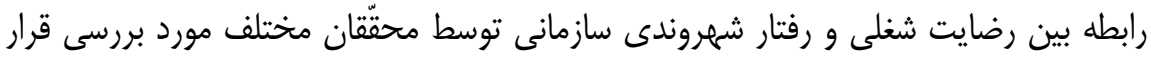

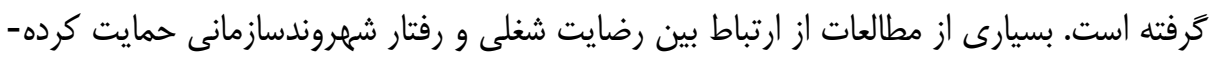
اند (Singh \& Singh, 2019). به عنوان مثال، (1991) Williams \& Anderson)

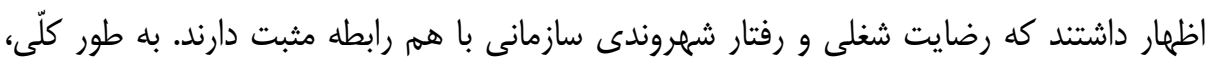

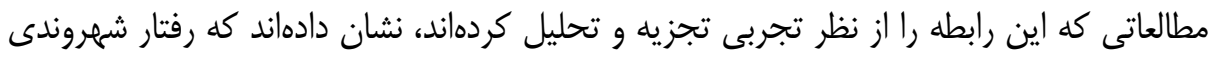

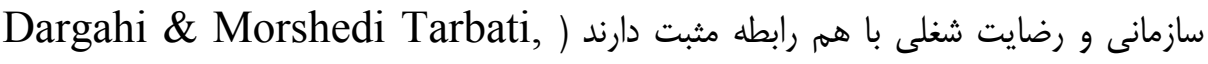
2017; Mirmoini \& et al, 2016; Nadi \& Esmaeili Harandi, 2017; (Nadiri \& Tanova, 2010; Adamy, 2018 به دليل روابط متقابلى كه بين رضايت و رفتار شهروندى سازمانى وجود دارد (Podsakoff \& et al, 1993)، بعيد است محقّان

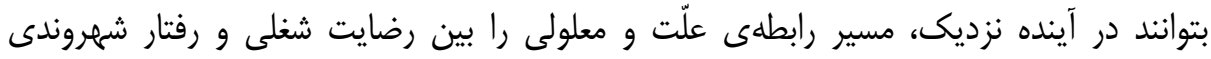

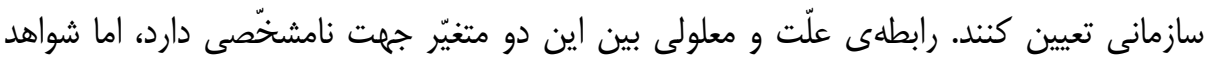

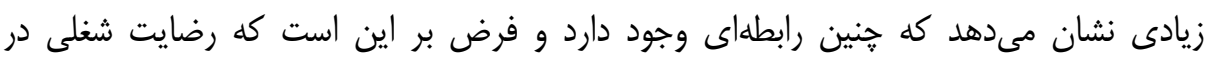

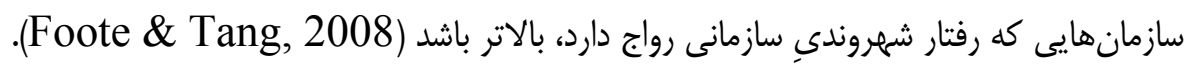

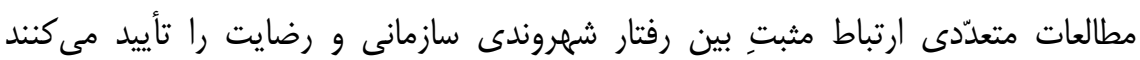
Meynhardt, Brieger \& Hermann, 2020; Lambert, 2010; Davila \& ) Finkelstein, 2013; Belwalkar Vohra \& Pandey, 2018 ( رقتار شهروندى \& \&

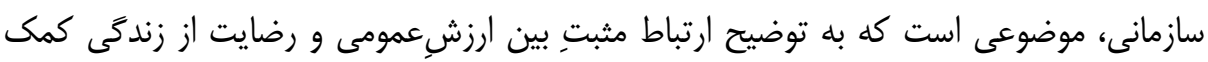
مى كند (Meynhardt, Brieger \& Hermann, 2020, P. 1562) Lambert(2010) در يك مطالعه نشان داد كه رفتار شهروندى سازمانى با رضايت از زندكى ماركى

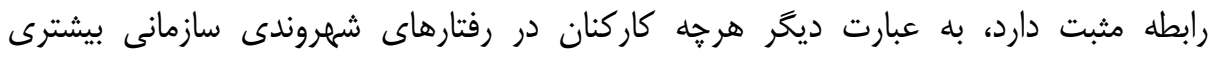




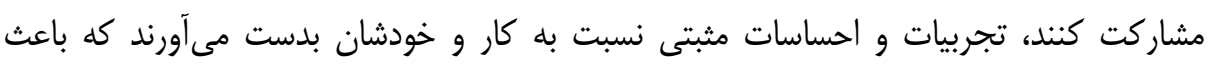

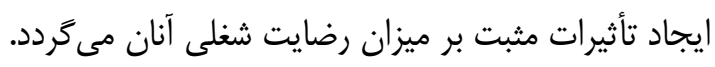

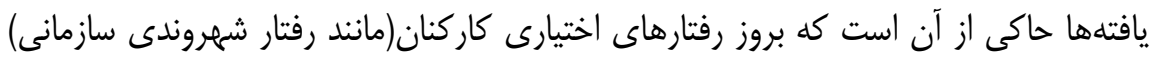

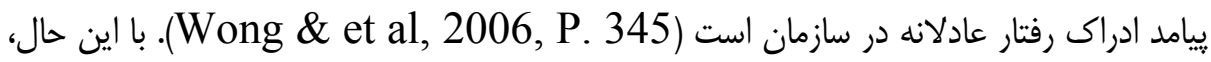

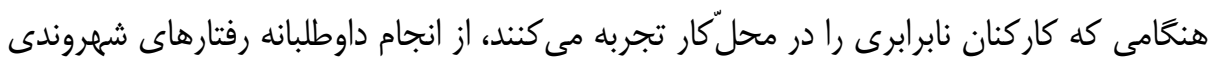

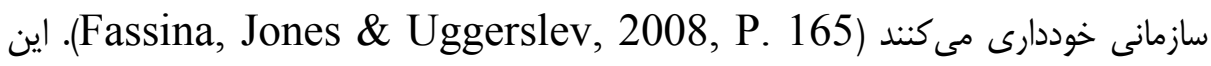

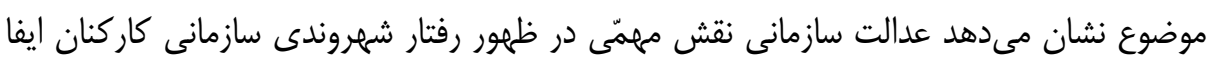

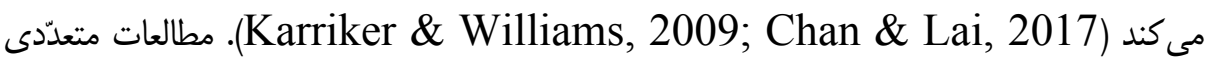

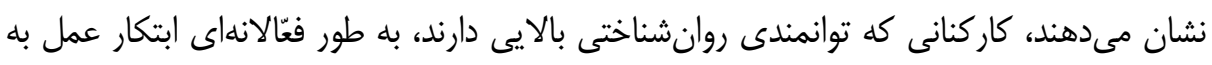

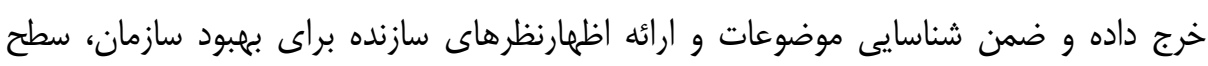
بالايى از مشاركت را از خود نشان مى نهند (Frazier \& Fainshmidt, 2012, P. 696).

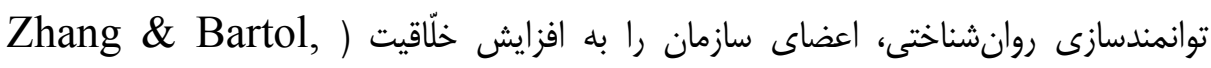

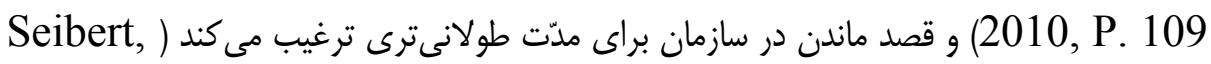
(Wang \& Courtright, 2011

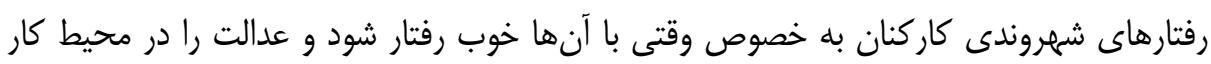

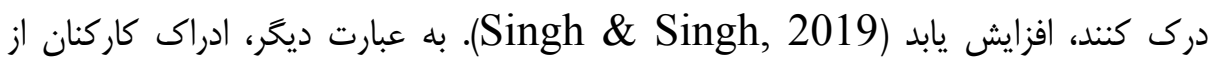

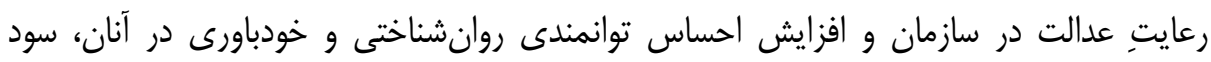

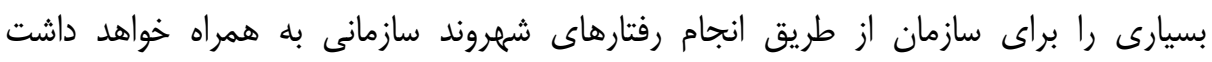
(Safarzadeh \& et al, 2017, P. 59)

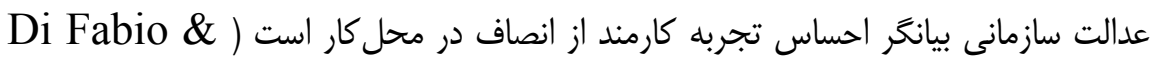
Palazzeschi, 2012, P. 33

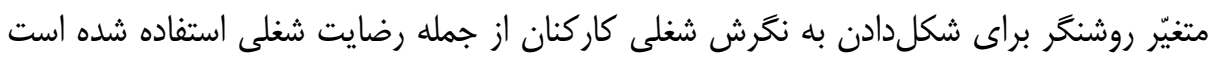
Nadiri \& Tanova, 2010; Clay-Warner, Reynolds \& Roman, 2005; ) Aryee, Budhwar \& Chen, 2002

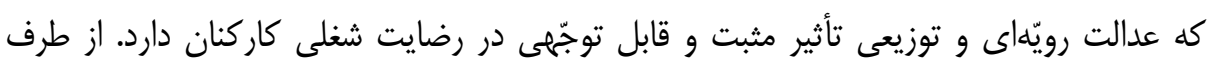

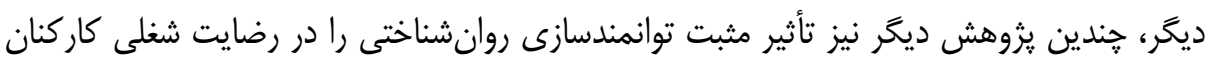

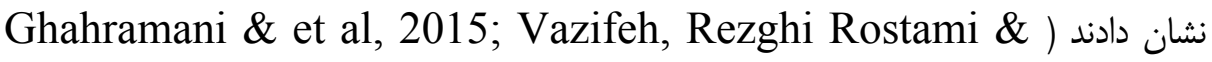


Pakdel, 2019; Seibert, Wang \& Courtright, 2011; Amundsen \& .(Martinsen, 2015; Idris, See \& Coughlan, 2018; Aldaihani, 2019

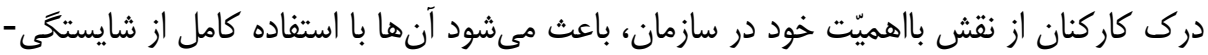

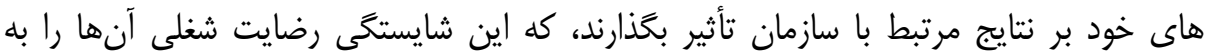

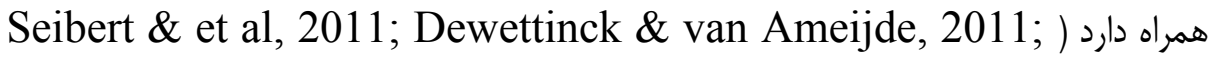

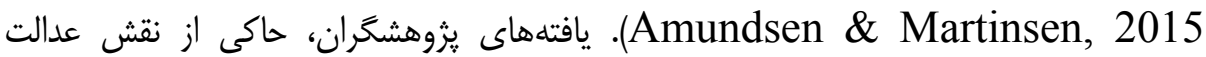
Nadiri \& Tanova, 2010; Di Fabio \& ) سازمانى در ميزان رضايت شغلى \& (A) و) (Palazzeschi, 2012; Clay-Warner, Reynolds \& Roman, 2005 Seibert, Wang توانمندسازى روانشناختى در افزايش سطح رضايت شغلى كاركنان مى اشاشد \& Courtright, 2011; Dewettinck \& van Ameijde, 2011; Amundsen \& Martinsen, 2015 Singh \& ( غيرمستقيم از طريق توانمندسازى روانشناختى بر رضايت شغلى تأثير بكذاردان

.Singh, 2019

در يك مطالعهى فراتحليل، Colquitt \& et al(2001) مشاهده كردند كه بين احساس

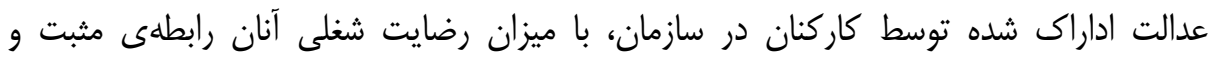

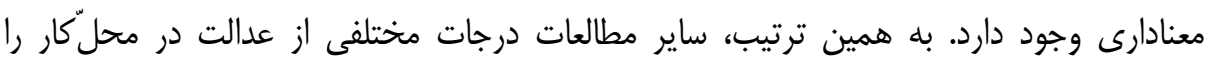

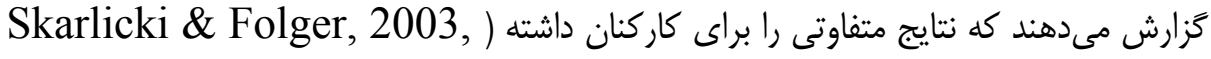
(P. 3

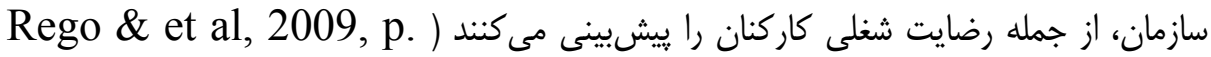

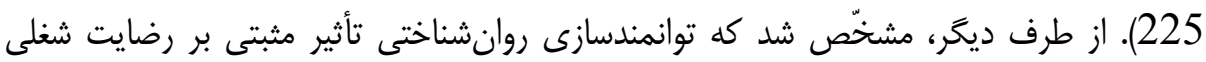

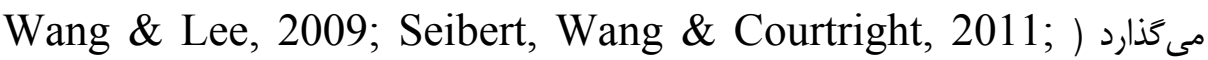
Seibert, Wang \& Holdsworth \& Cartwright, 2003

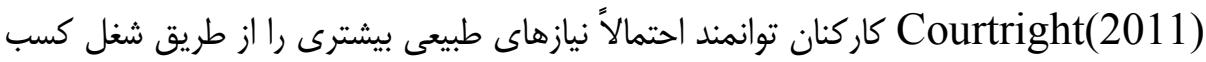

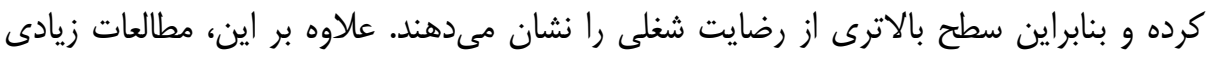

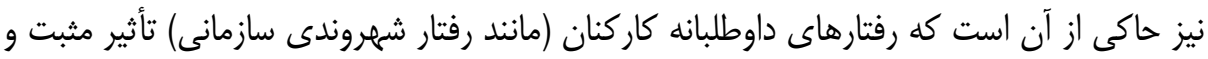

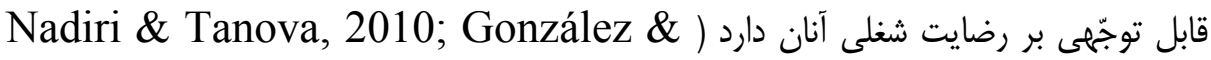

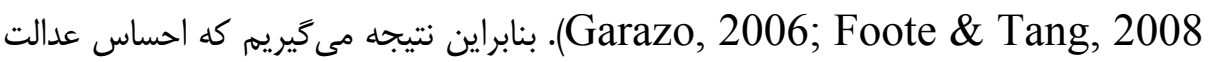

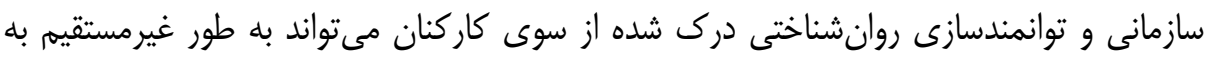




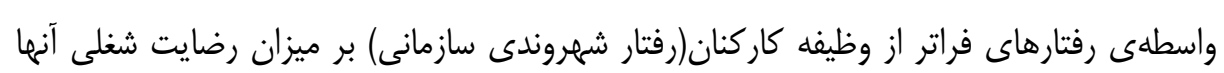

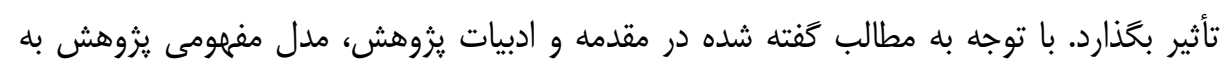

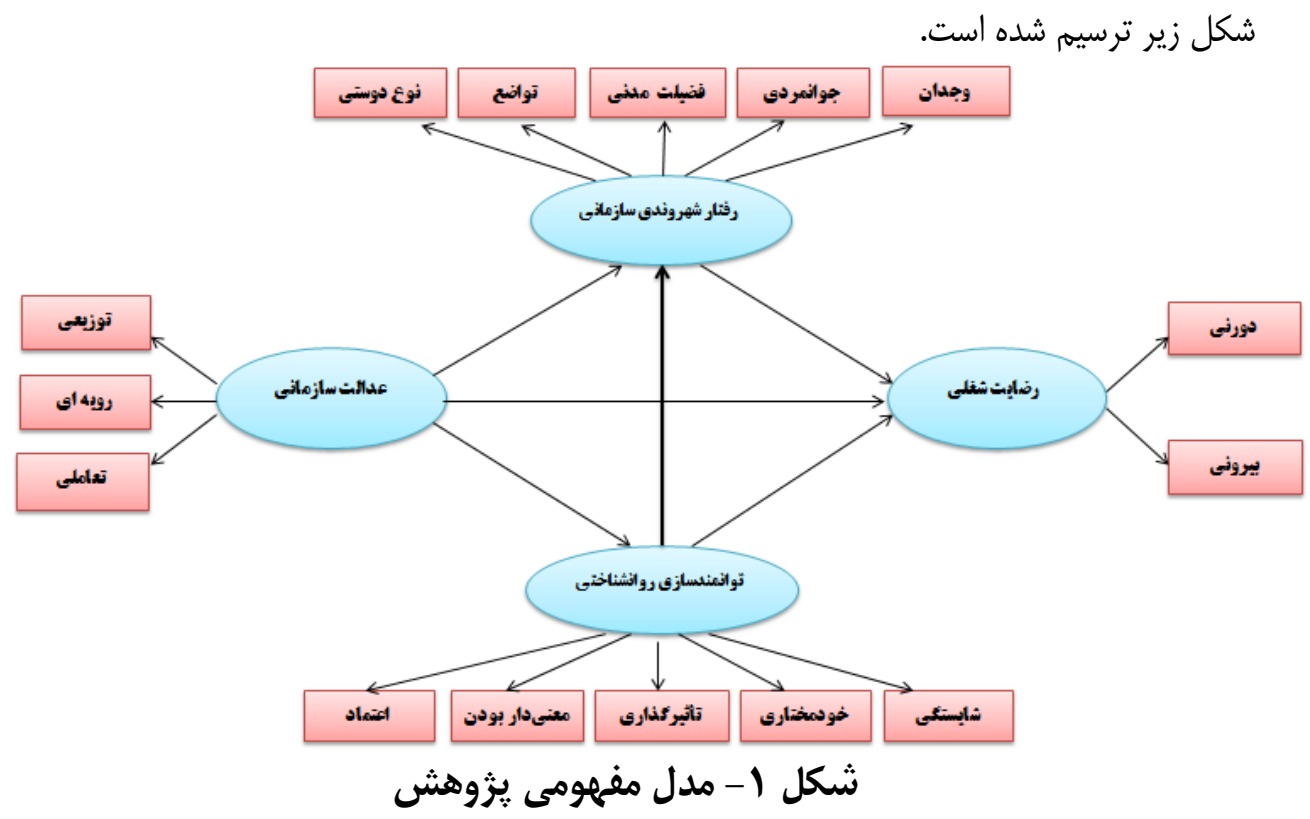

فرضيات يزوهش

فرضيه اول: عدالت سازمانى تأثير مستقيم و معنادار بر رضايت شغلى دارد.

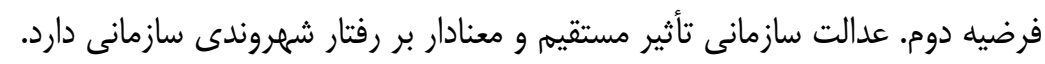

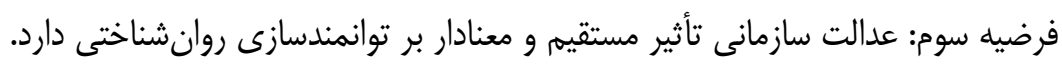

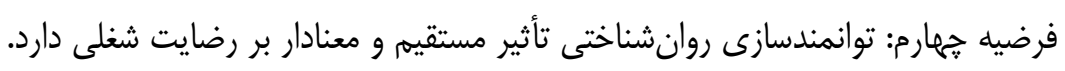

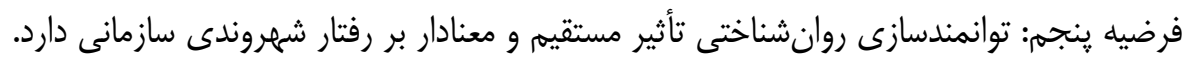

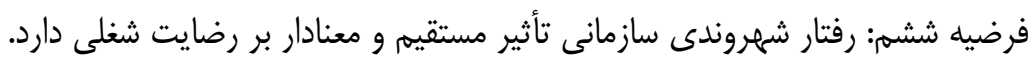

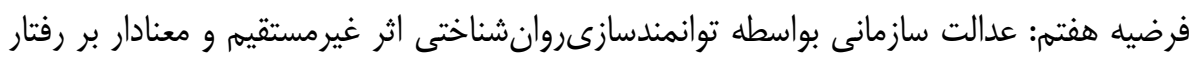
شهروندى سازمانى دارد. فرضيه هشته: عدالت سازمانى بواسطه توانمندسازى روانشناختى اثر غيرمستقيم و معنادار بر رضايت شغلى دارد. 
فرضيه نهم: عدالت سازمانى بواسطه رفتار شهروندى سازمانى اثر غيرمستقيم و معنادار بر رضايت شغلى دارد.

فرضيه دهم: توانمندسازى روانشناختى بواسطه رفتار شهروندى سازمانى اثر غيرمستقيم و معنادار بر رضايت شغلى دارد.

\section{روش شناسى : روز}

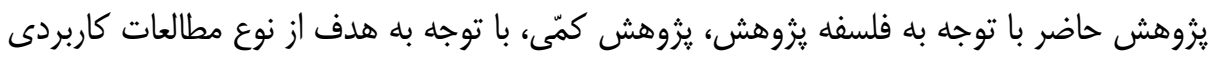

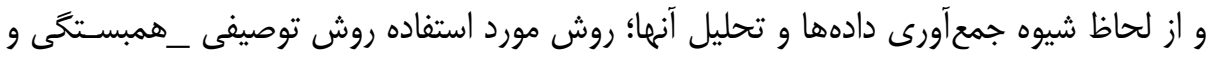

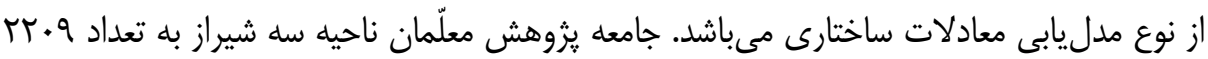

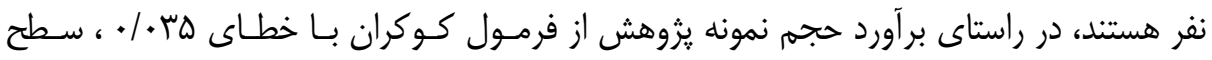

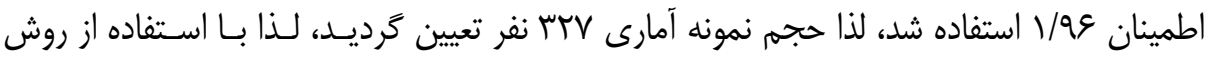

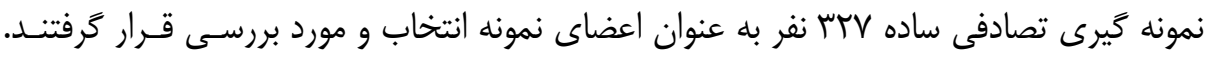

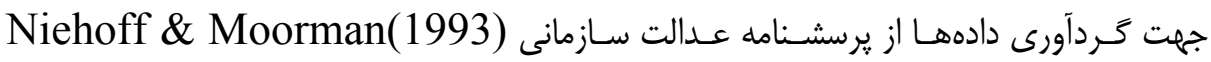

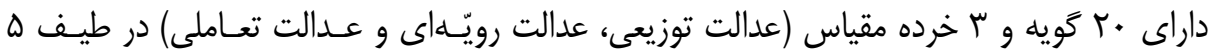

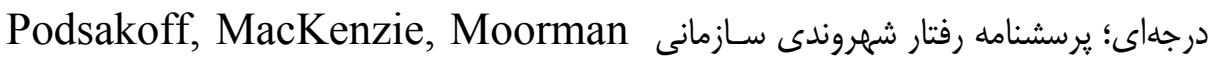

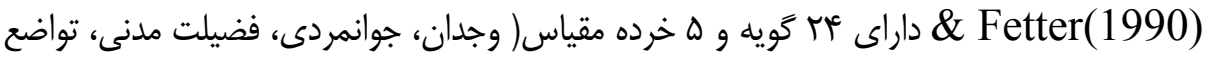

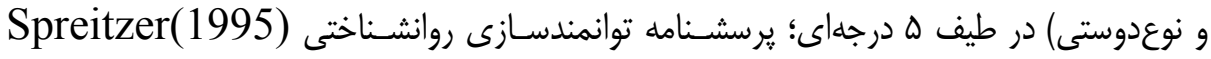

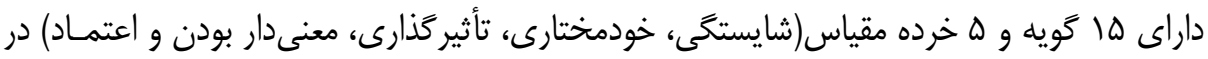

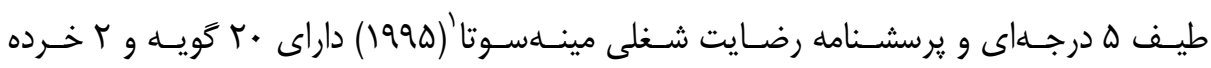

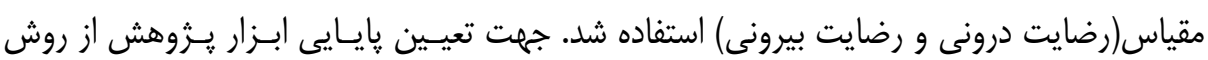

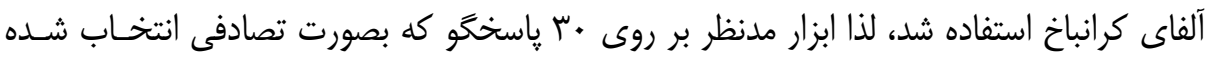
بودند اجراو سيس ضرايب پِايايى محاسبه شد.

1. Minesota Job satisfaction quastionair 
نقش عدالت سازمانى ...... ا(دلان،معمونى

جدول ا - ضرايب يايايى ابزار يزوهش

\begin{tabular}{|c|c|c|c|}
\hline آلفاى كر انباخ & شماره سوالات & تعداد & متغيرها \\
\hline . & $1-4$. & $r$. & عدالت سازمانى \\
\hline.$/ 90$ & $1-M \varphi^{c}$ & TF & رفتار شهروندى سازمانى \\
\hline.$/ 9$. & $1-10$ & 10 & توانمندسازى روانشناختى \\
\hline.$/ 94$ & $1-r$. & $r$. & رضايت شغلى \\
\hline
\end{tabular}

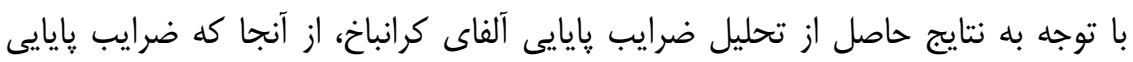

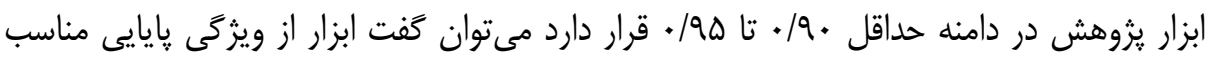
برخوردار است. جهت تعيين روايى ابزار از تكنيك تحليل عاملى تأييدى استفاده شد.

جدول r-شاخصهاى برازندكى تحليل عاملى تأييدى مرتبه اول ابزار يزوهش رفتار شهروندى سازمانى عدالت سازمانى ملاكى شاخص

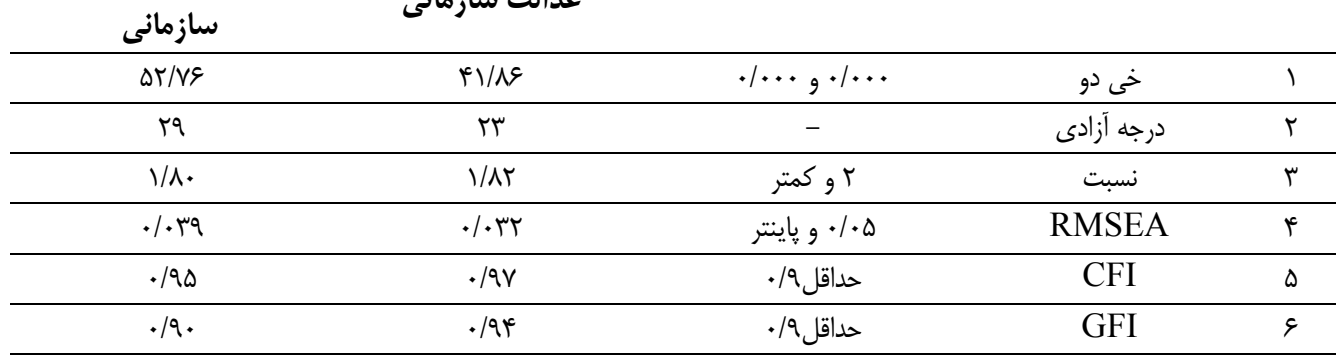

جدول r- شاخصهاى برازندىّى تحليل عاملى تأييدى مر تبه اول ابزار بزووهش

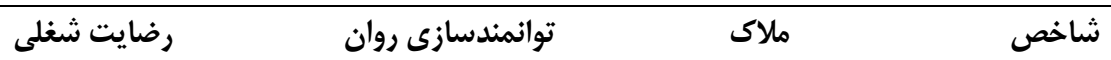
شناختى

\begin{tabular}{|c|c|c|c|c|}
\hline$r N / v$ & $r q / 99$ & $* / \cdots, \cdot / \cdots$ & خى دو & 1 \\
\hline rt & $r$. & - & درجه آزادى & $r$ \\
\hline I/VD & $1 / 91$ & ז و كمتر & نسبت & r \\
\hline .1 .49 & .1 .48 & هـ/• و پاينتر & RMSEA & r \\
\hline.$/ 99$ &.$/ 99$ & حداقل19. & CFI & $\Delta$ \\
\hline.$/ 94$ &.$/ 9 \pi$ & حداقل19. & GFI & 9 \\
\hline
\end{tabular}


با توجه به نتايج حاصل از شاخصهاى برازندگى در مدلهاى اندازمخيرى تحليل عاملى إزلى

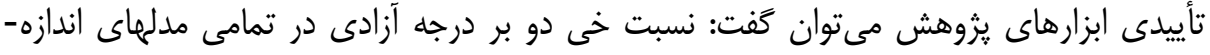

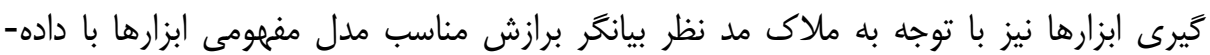

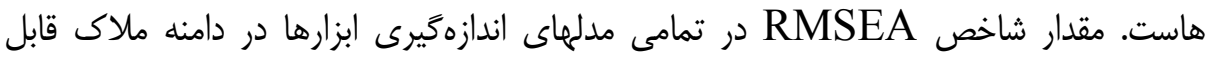

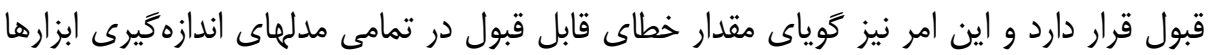

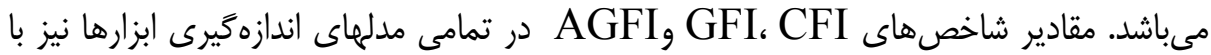

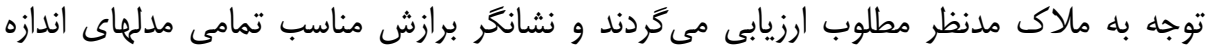

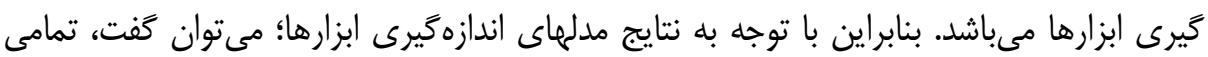

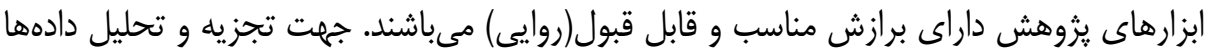

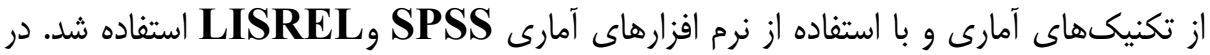

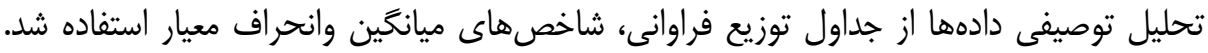

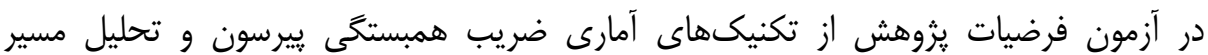
تأييدى استفاده شد.

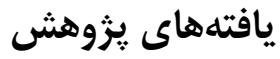
الف: تحليل توصيفى متغيرهاى يثوهش يُوهن جدول ع-بررسى توصيفى وضعيت متغير هاى يزوهش

\begin{tabular}{|c|c|c|c|}
\hline انحراف استاندارد & ميانغَين & فراوانى & متغير \\
\hline$\cdot / \Lambda \cdot t^{2}$ & $r / r q$ & TrV & عدالت سازمانى OJ \\
\hline$\cdot /$ veq & T/Tr & rTr & OCB رفتار شهروندى سازمانى \\
\hline.$/ 910$ & $r / \backslash 9$ & rTY & توانمند سازى روانشناختى PE \\
\hline.$/ V I I$ & $\Gamma / M$ & TTV & رضايت شغلىJS \\
\hline
\end{tabular}

ب: تحليل ماتريس همبستخى متغيرهاى يزوهش 
نقش عدالت سازمانى ...... ا(دلان،معمونى

\begin{tabular}{|c|c|c|c|c|}
\hline \multirow[t]{4}{*}{ JS } & $\mathrm{PE}$ & $\mathrm{OCB}$ & OJ & \\
\hline & & & - & عدالت سازمانى OJ \\
\hline & & - & $* \cdot 19 V$ & OCB رفتار شعوندى سازمانى \\
\hline & - & $* / 09$ & $* / V^{2}$ & PE توانمند سازى روانشناختى \\
\hline- & $* \cdot / \Delta r$ & $* \cdot|9|$ & $* \cdot / \Delta \varphi$ & رضايت شغلى JS \\
\hline
\end{tabular}

متغير عدالت سازمانى داراى رابطه مثبت و معنادار در سطح ه • / با متغيرهاى رفتار شهروندى

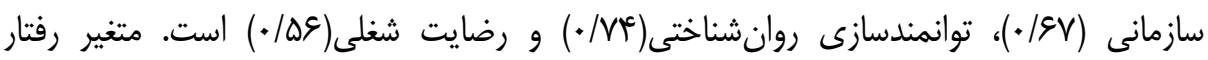
شهروندى سازمانى داراى رابطه مثبت و معنادار در سطح هـ/ • با متغيرهاى توانمندسازى روان

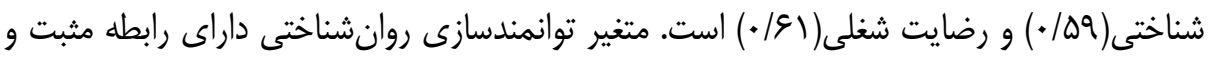

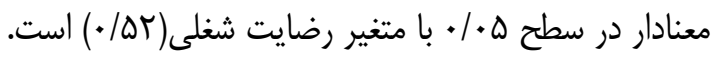

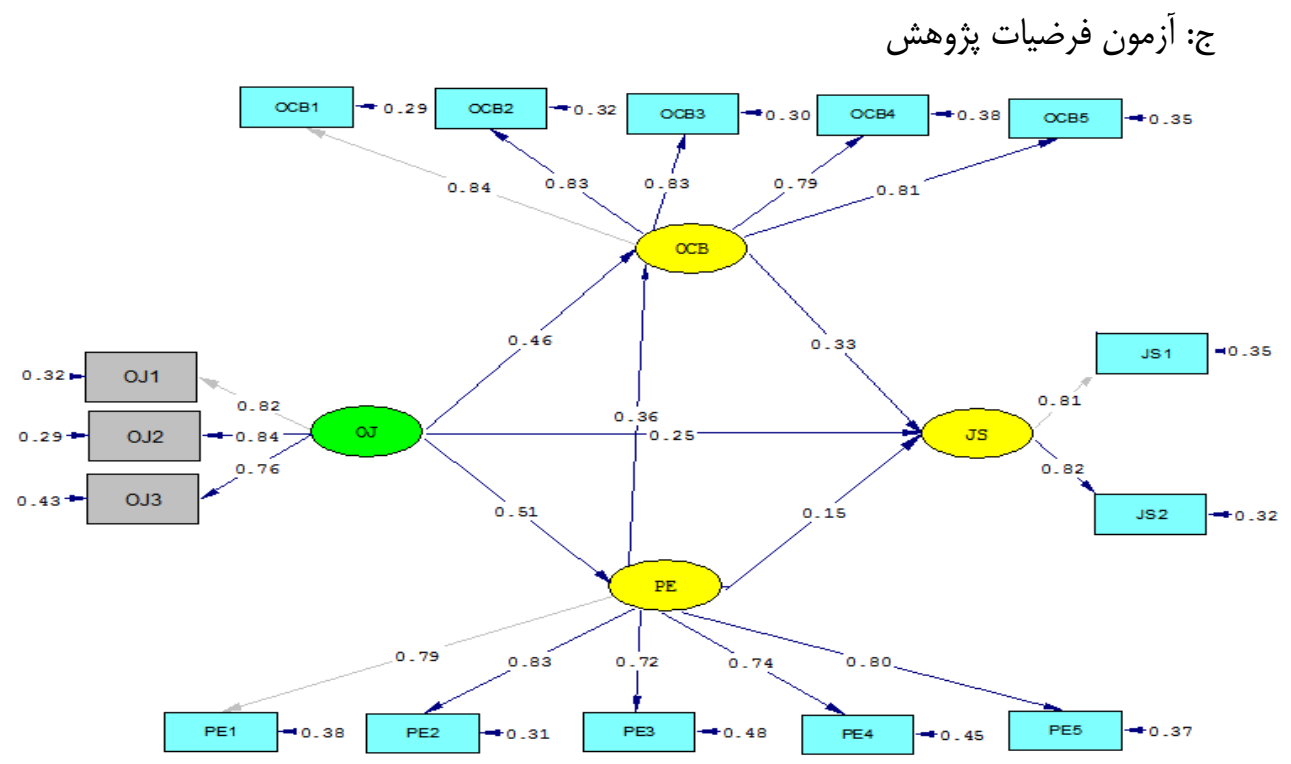

Chi-Square $=156.24, d f=84, \mathrm{P}-\mathrm{value}=0.00000, \mathrm{RMSEA}=0.048$

شكل r - مدل تجربى با ضر ايب استاندارد شده 


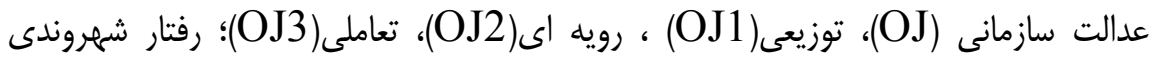

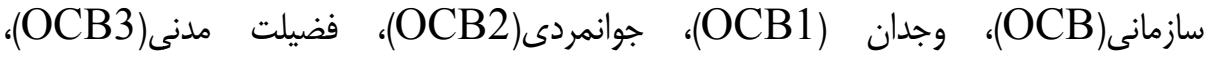

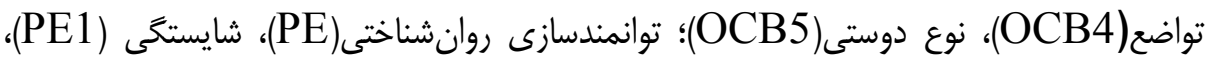

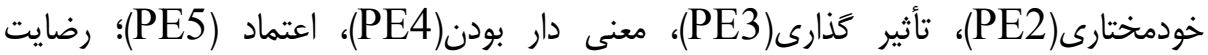
شغلى(JS)، رضايت درونى (JS1)، (JS2)، رضايت بيرونى (JS2).

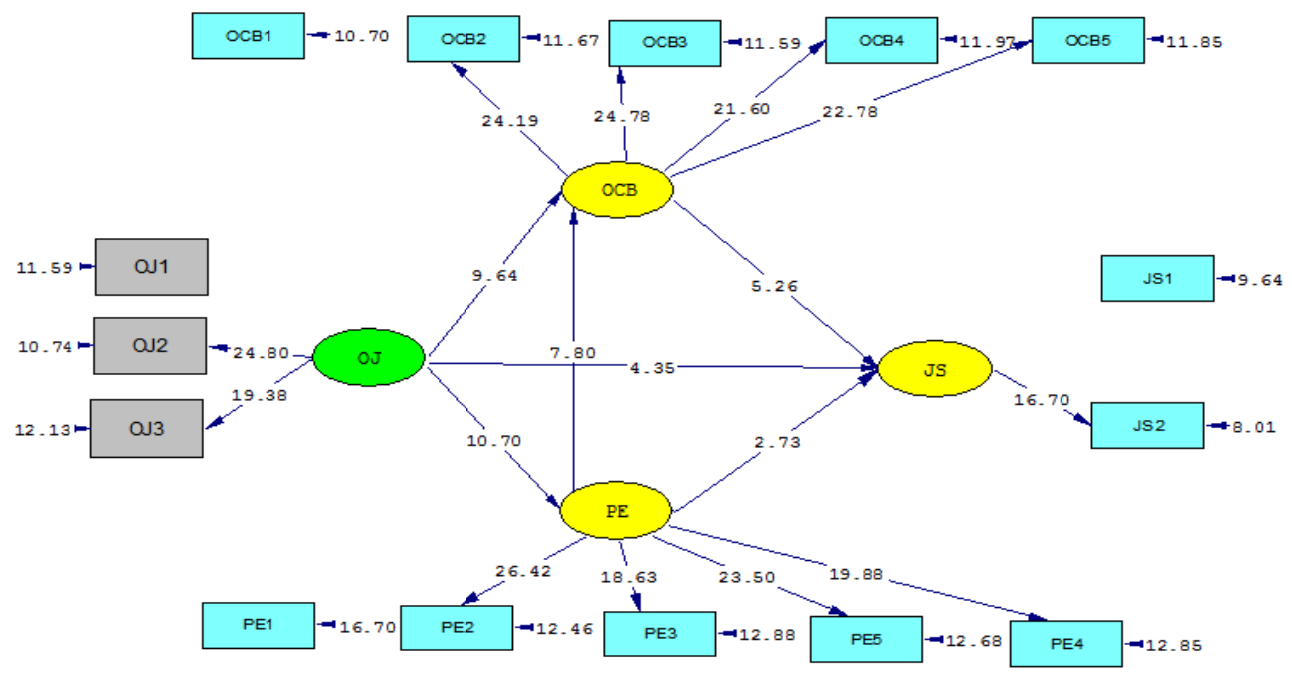

Chi-Square $=156.24, \mathrm{df}=84, \mathrm{P}-\mathrm{value}=0.00000, \mathrm{RMSEA}=0.048$

\section{شكل س- مدل تجربى با مقادير شاخص T}

فرضيه اول: عدالت سازمانى تأثير مستقيم و معنادار بر رضايت شغلى دارد.

جدول 7- ضرايب مسير مستقيم عدالت سازمانى بر رضايت شغلى منفي

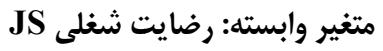

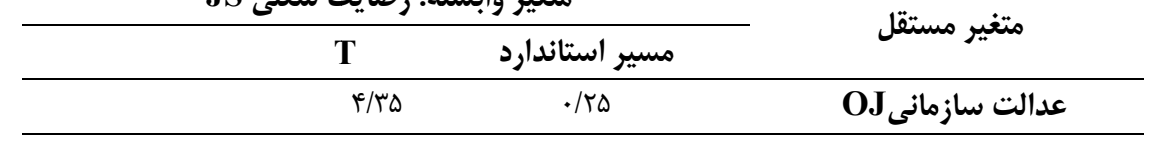


نقش عدالت سازمانى ...... اردلات،دعمونى

متغير عدالت سازمانى با ضريب مسير مستقيم (ه//•) و مقدار تى(هس/ז) داراى اثر مستقيه، مثبت و معنادار بر متغير رضايت شغلى در سطح هـ ـ • مىباشد.

فرضيه دوم: عدالت سازمانى تأثير مستقيم و معنادار بر رفتار شهروندى سازمانى دارد.

جدول V- ضرايب مسير مستقيم عدالت سازمانى بر رفتار شمروندى سازمانى

\begin{tabular}{|c|c|c|}
\hline \multicolumn{2}{|c|}{ متغير وابسته: رفتار شهروندى سازمانى OCB } & \multirow{2}{*}{ 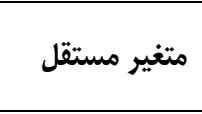 } \\
\hline $\mathbf{T}$ & مسير استاندارد & \\
\hline $9 / 94$ &.$/ 48$ & OJ. \\
\hline
\end{tabular}

متغير عدالت سازمانى با ضريب مسير مستقيم (و\&/•) و مقدار تى(أو/9) داراى اثر مستقيه،

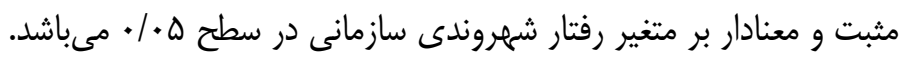

فرضيه سوم: عدالت سازمانى تأثير مستقيم و معنادار بر توانمندسازى روانشناختى دارد.

جدول 1- ضرايب مسير مستقيم عدالت سازمانى بر توانمند سازى روانشناختى

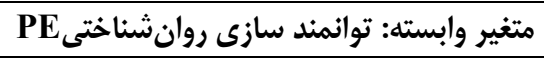

\begin{tabular}{|c|c|c|c|}
\hline & $\mathbf{T}$ & مسير استاندارد & متغير مستقل \\
\hline & $1 \cdot / \mathrm{V}$ &.$|0|$ & عدالت سازمانى \\
\hline
\end{tabular}

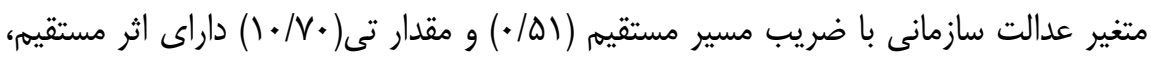
مثبت و معنادار بر متغير توانمندسازى روانشناختى در سطح هـ • • مىباشد.

فرضيه جههارم: توانمندسازى روانشناختى تأثير مستقيم و معنادار بر رضايت شغلى دارد.

جدول 9- ضرايب مسير مستقيم توانمندسازى روانشناختى بر رضايت شغلى

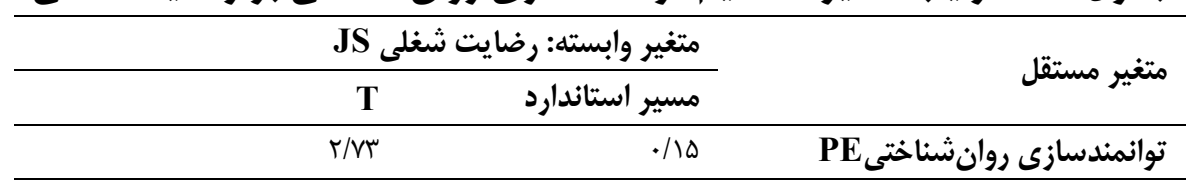




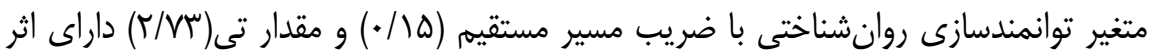

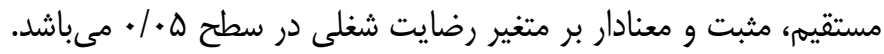

فرضيه ينجم: توانمندسازى روانشناختى تأثير مستقيم و معنادار بر رفتار شهروندى سازمانى دارد.

جدول + ( - ضرايب مسير مستقيه توانمندسازى روانشناختى بر رفتار

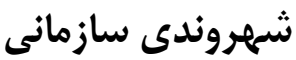

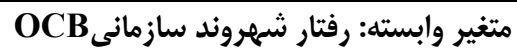

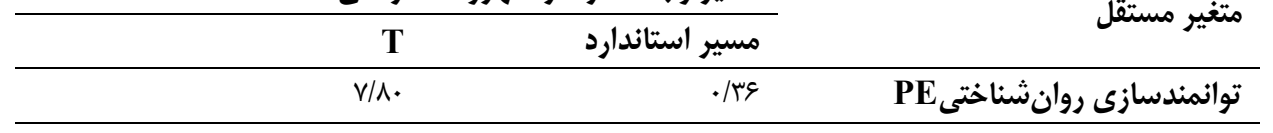

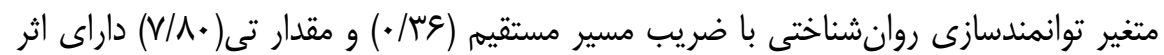

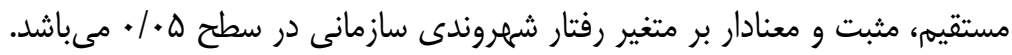

فرضيه ششم: رفتار شهروندى سازمانى تأثير مستقيه و معنادار بر رضايت شغلى دارد.

جدول || - ضرايب مسير مستقيه رفتار شهروندى سازمانى بر رضايت شغلى

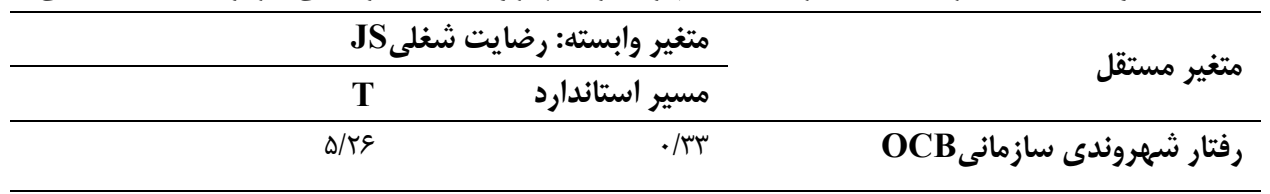

متغير رفتار شهروندى سازمانى با ضريب مسير مستقيم (سس/•) و مقدار تى(ع/هاه) داراى اثر

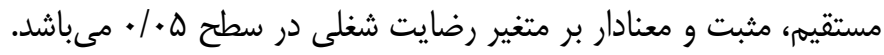

فرضيه هفتم: عدالت سازمانى بواسطه توانمندسازى روانشناختى اثر غير مستقيه و معنادار بر رفتار شهروندى سازمانى دارد. 
نقش عدالت سازمانى ...... اردلات،دعمونى

جدول T I - ضريب مسير غير مستقيم عدالت سازمانى بر رفتار شمروندى با ميانجى

متغير ميانجى: توانمندسازى روانشناختى PE - متريانير وابسته: رفتار شهروندى

\begin{tabular}{|c|c|c|}
\hline & سازمانى OCB & متغير مستقل \\
\hline $\mathbf{T}$ & مسير استاندارد & \\
\hline S/Tr & ./ר^r & OJ Oدالت سازمانى \\
\hline
\end{tabular}

متغير عدالت سازمانى با ضريب مسير غير مستقيه، بواسطه توانمندسازى روانشناختى

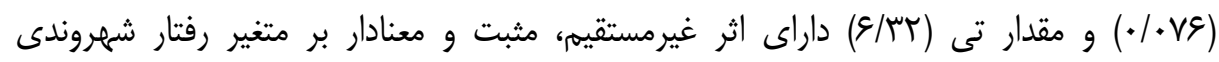
سازمانى در سطح ه+• • مىباشد.

فرضيه هشته: عدالت سازمانى بواسطه توانمندسازى روانشناختى اثر غير مستقيم و معنادار بر رضايت شغلى دارد.

جدول سا - ضريب مسير غير مستقيم عدالت سازمانى بر رضايت شغلى با ميانجى

\begin{tabular}{|c|c|c|}
\hline \multicolumn{2}{|c|}{ متغير ميانجى: توانمندسازى روانشناختى PE - متغير وابسته: رضايت شغلى JS } & \multirow{2}{*}{ متغير مستقل } \\
\hline T & مسير استاندارد & \\
\hline$r / 9 \Delta$ & $\cdot / \cdot v 9$ & عدالت سازمانى \\
\hline
\end{tabular}

متغير عدالت سازمانى با ضريب مسير غير مستقيم بواسطه توانمندسازى روانشناختى

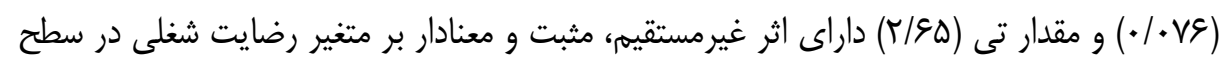

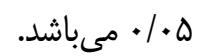

فرضيه نهم: عدالت سازمانى بواسطه رفتار شهروندى سازمانى اثر غير مستقيه و معنادار بر رضايت شغلى دارد. 
هديريت بر آهوزش سازمانها

جدول ع ( - ضريب مسير غير مستقيم عدالت سازمانى بر رضايت شغلى با

ميانجى ترى رفتار شهروندى سير سازمانى

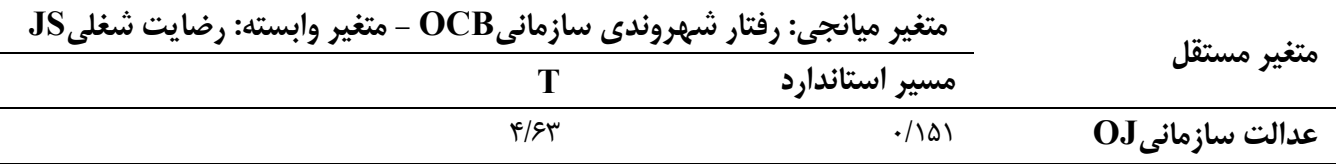

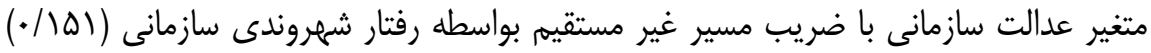

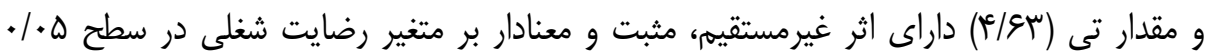

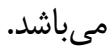

فرضيه دهم: توانمندسازى روانشناختى بواسطه رفتار شهروندى سازمانى اثر غير مستقيم و

معنادار بر رضايت شغلى دارد.

جدول 10 - ضريب مسير غير مستقيم توانمندسازى روانشناختى بر رضايت

شغلى با ميانجى

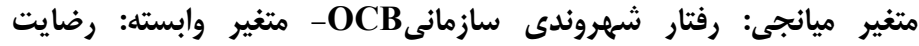

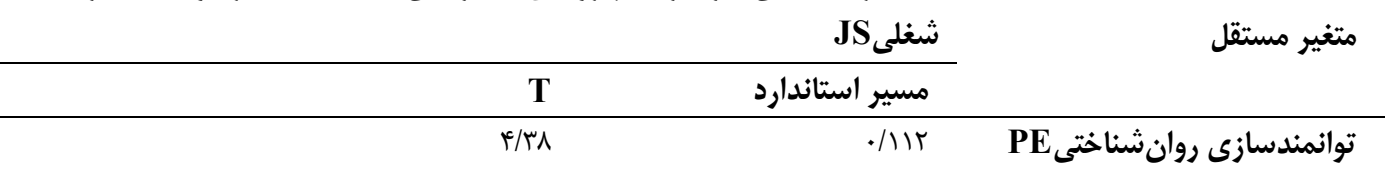

متغير توانمندسازى روانشناختى با ضريب مسير غير مستقيم بواسطه رفتار شهروندى سازمانى

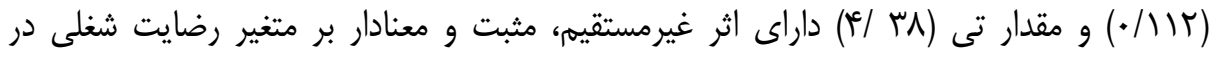
سطح ه • • مىباشد. 
نقش عدالت سازمانى ...... ا(دلان،معمونى

\begin{tabular}{|c|c|c|c|}
\hline بر آورد & ملاك & شاخص & \\
\hline$I \Delta F / K F$ & $.1 \cdots$ & خى دو & 1 \\
\hline Nif & - & درجه آزادى & $r$ \\
\hline $1 / \wedge \varepsilon$ & rو كمتر & نسبت & r \\
\hline$\cdot 1 \cdot+\wedge$ & هـ/• و پاينتر & RMSEA & f \\
\hline.$/ 99$ & حداقل 9/. & CFI & $\Delta$ \\
\hline.$/ 94$ & حداقل 1 • & GFI & 8 \\
\hline.$/ 94$ & حداقل 9/. & AFGI & $\checkmark$ \\
\hline
\end{tabular}

با توجه به نتايج حاصل از شاخصهاى برازندگى در مدل تحليل مسير تأييدى يزوهش

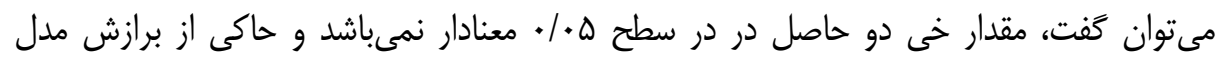

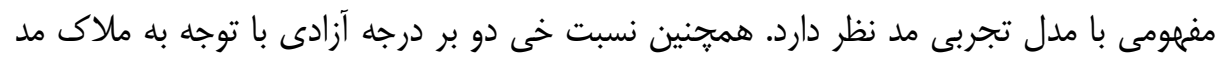

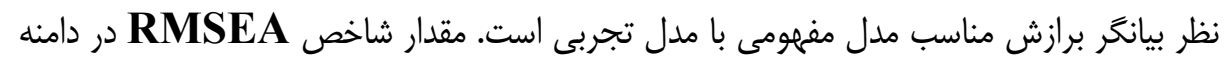

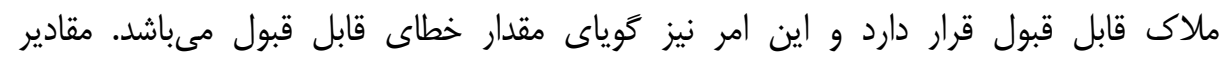

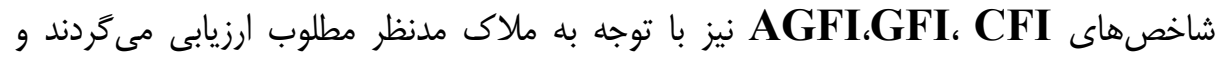

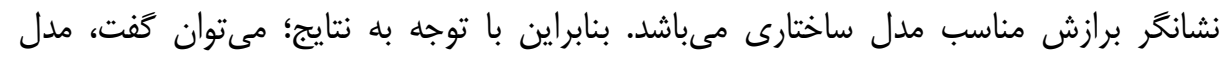

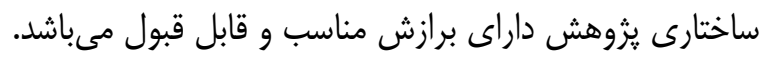
بررسى اثرات مستقيه، غير مستقيه و كل:

جدول IV - ضرايب مسير معنادار ( مستقيم، غير مستقيم و كل) متغير هاى

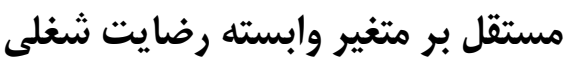

\begin{tabular}{|c|c|c|c|}
\hline \multicolumn{4}{|c|}{ متغير وابسته: رضايت شغلى JS } \\
\hline & \multicolumn{2}{|c|}{ اثرات استاندارد شده } & \multirow[t]{2}{*}{ متغير مستقل } \\
\hline 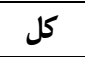 & غير مستقيم & مستقيم & \\
\hline . $/ \Delta T Y$ &.$/ T A Y$ &.$/ T \Delta$ & عدالت سازمانى OJ \\
\hline 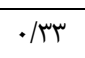 & - & 每 & رفتار شهروندى سازمانى OCB \\
\hline . TET &.$/ 114$ & .110 & توانمندسازى روانشناختى PE \\
\hline \multicolumn{2}{|c|}{.19} & & واريانس تبيين شده \\
\hline \multicolumn{2}{|c|}{$9 / 1$} & & مقدار T T T T T \\
\hline
\end{tabular}


هديريت بر آهوزش سازماذها

جدول 1 | - ضر ايب مسير معنادار( مستقيم، غير مستقيم و كل) متغيرهاى

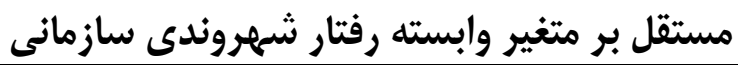

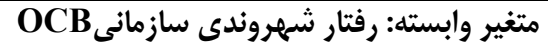

\begin{tabular}{|c|c|c|c|}
\hline & \multicolumn{2}{|c|}{ اثرات استاندارد شده } & \multirow[t]{2}{*}{ متغير مستقل } \\
\hline كل & غير مستقيم & مستقيم & \\
\hline ת4 &.$/ \mathrm{AN}$ &.$/ 48$ & عدالت سازمانى OJ \\
\hline 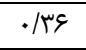 & - & ع צ & PE توانمندسازى روانشناختى \\
\hline \multicolumn{2}{|c|}{.$/ 49$} & & واريانس تبيين شده \\
\hline & & & مقدار T \\
\hline
\end{tabular}

جدول 9 - ضر ايب مسير معنادار( مستقيم، غير مستقيم و كل) متغير هاى

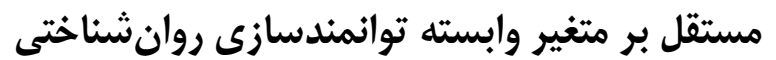

\begin{tabular}{|c|c|c|c|}
\hline \multicolumn{3}{|c|}{ متغير وابسته: توانمندسازى روانشناختى PE } & \multirow{3}{*}{ متغير مستقل } \\
\hline \multirow[b]{2}{*}{ 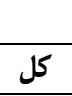 } & \multicolumn{2}{|c|}{ اثرات استاندارد شده } & \\
\hline & غير مستقيم & 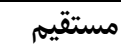 & \\
\hline.$|0|$ & - & $\cdot|\Delta|$ & عدالت سازمانى OJ \\
\hline \multicolumn{2}{|c|}{$\cdot / \mathrm{N}^{\mathrm{c}}$} & & واريانس تبيين شده \\
\hline \multicolumn{2}{|c|}{$1 \% / 19$} & & مقدار T T T \\
\hline
\end{tabular}

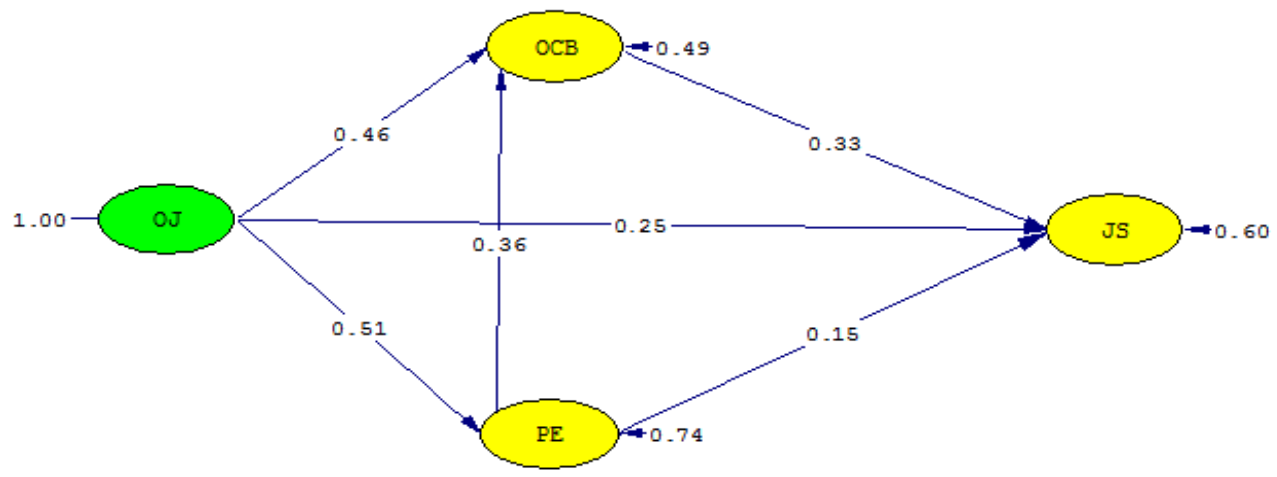

Chi-Square=156.24, df=84, P-value=0.00000, $\mathrm{FMSEA}=0.048$

شكل ع- واريانس تبيين شده متغيرهاى وابسته و ميانجى

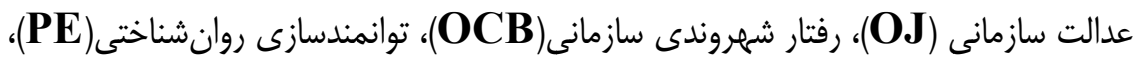

$$
\text { رضايت شغلى(JS) }
$$




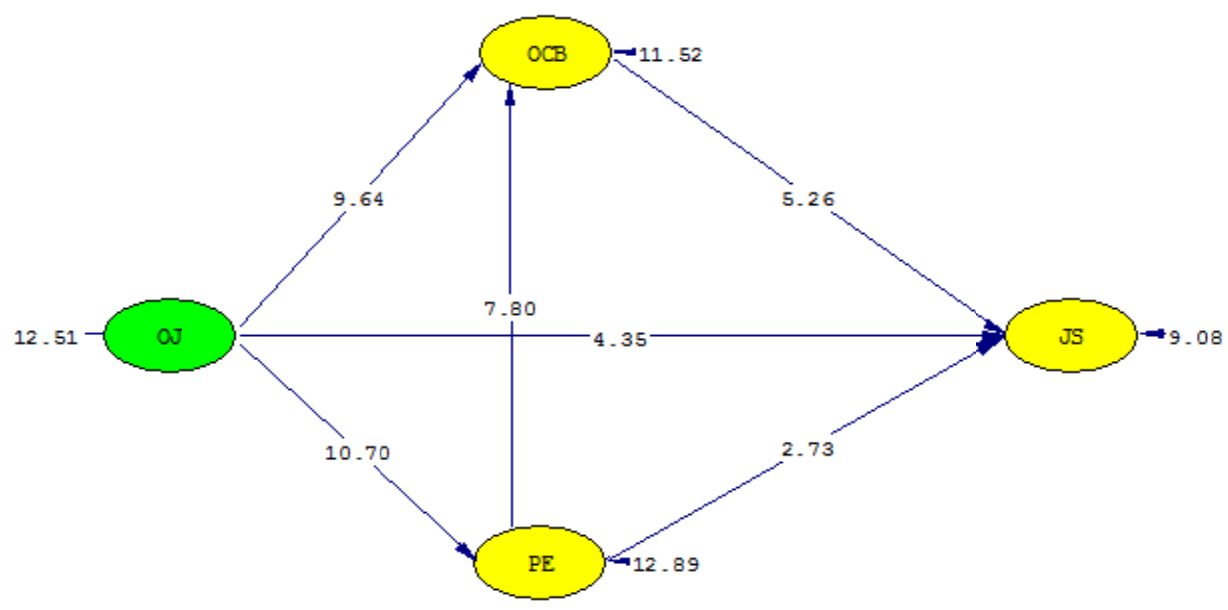

Chi-Square $=156.24, \mathrm{df}=84, \mathrm{P}-\mathrm{value}=0.00000, \mathrm{RMSEA}=0.048$

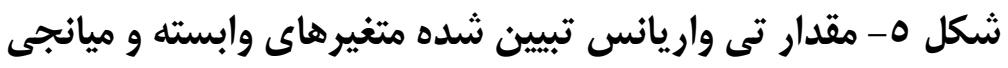

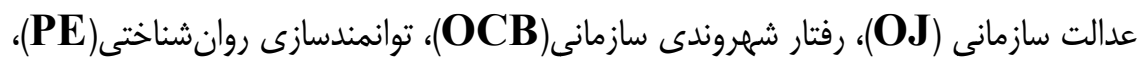
رضايت شغلى(JS)

بحث و نتيجه

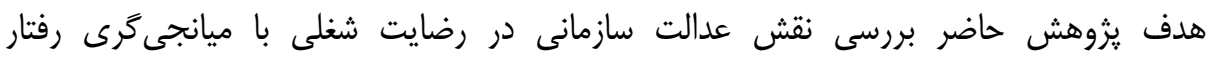

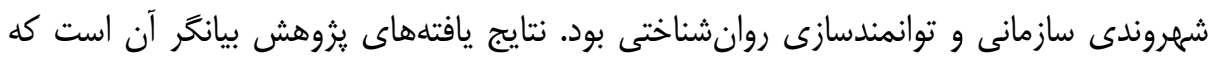
ادراك عدالت سازمانى بر رضايت شغلى ( Nadi \& Esmaeili Harandi, 2017 Gholampour \& Pourshafei, 2018; Nazari \& Rafei, 2018; Colquitt \& et al,2001; Madera, Dawson \& Guchait, 2016; Singhry, 2018; Naderi \& ) توانمندسازى روانشناختى (Suifan, Diab \& Abdallah, 2017 Saffarzadeh, 2014; Zahednezhad \& et al, 2015; Eidy \& et al, (2018; Lee, Kim \& Kim, 2016; Muqadas, Rehman \& Aslam, 2017 و وفتار شهروندى سازمانى كاركنان تأثير مستقيه، مثبت و معنادارى دارد ( Rahman Sarsat \& Janidi Jafari, 2018; Moradi \& et al, 2019; Fassina, Jones \& Uggerslev, 2008; Gupta \& Singh, 2013; Takeuchi, Bolino \& Lin, .2015; Gao \& He, 2017; Chan \& Lai, 2017; Ahmad \& et al, 2019 
به همين ترتيب، يافتهاى يزوهش از اين فران فرضيه حمايت مى كند كه درك توانمندسازى روان

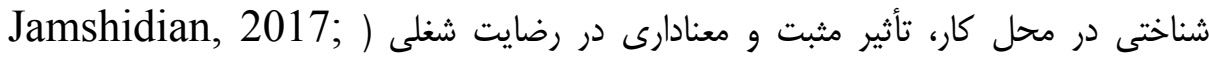
Vazifeh, Rezghi Rostami \& Pakdel, 2019; Wang \& Lee, 2009; Seibert, Wang \& Courtright, 2011; Idris, See \& Coughlan, 2018; Mohammadkhani \& et ) و رفتار شهروندى سازمانى كاركنان (Aldaihani, 2019 al, 2013; Safari \& et al, 2016; Salimi \& Abdi, 2018; Frazier \& Fainshmidt, 2012; Zhang \& Bartol, 2010; Arefin, Arif \& Raquib, 2015; Ioannidou, Karagiorgos \& Alexandris, 2016; Newman \& et (al, 2017 دارد. همجنين يافتهى ديخر يثوهش نشان داد كه رفتار شهروندى سازمانى تأثير

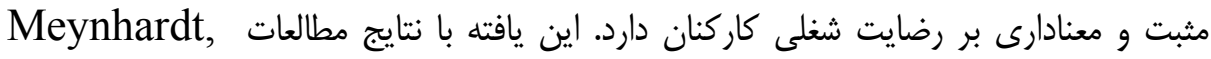
Foote \& ؛Davila \& Finkelstein, 2013 ؛Brieger \& Hermann(2020)

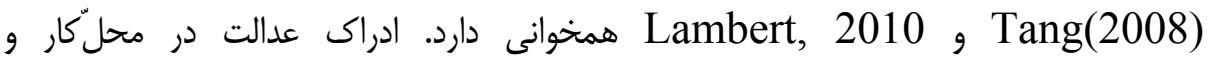

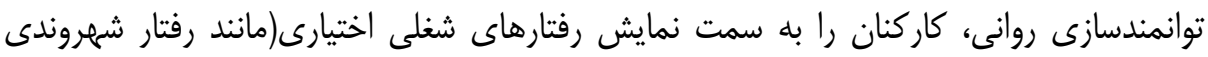

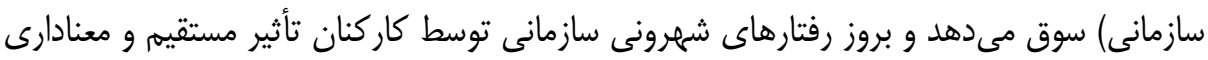
بر ميزان رضايت شغلى آنها مى كذارد (Singh \& Singh, 2019).

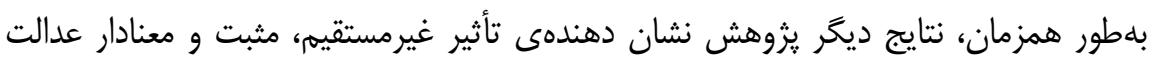

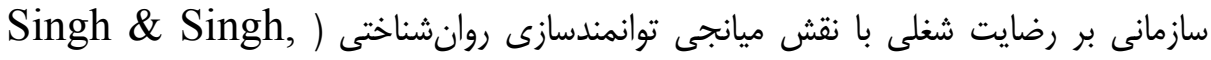

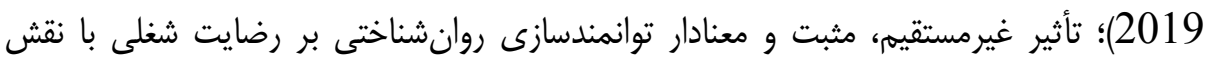

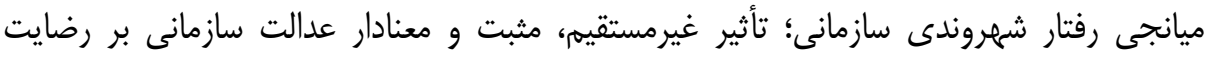

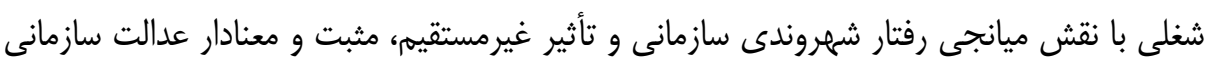

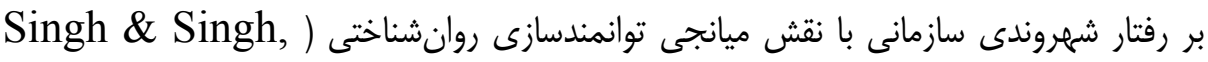

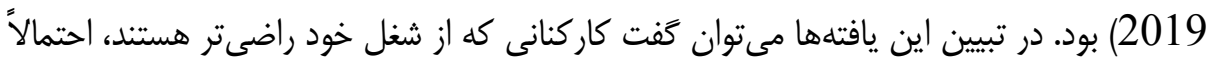

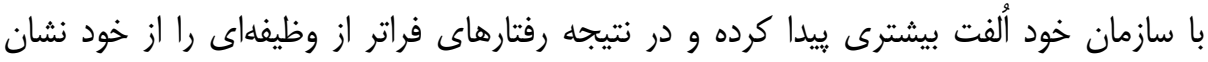

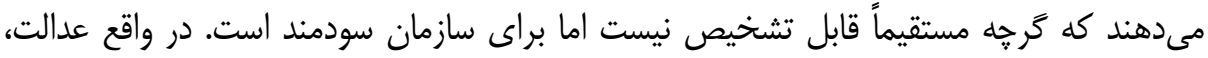

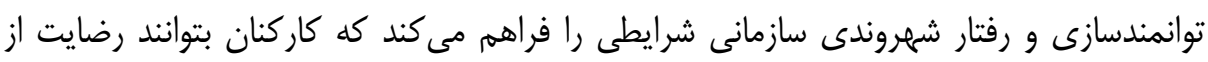

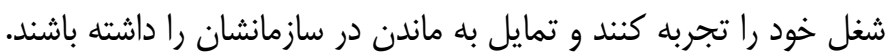

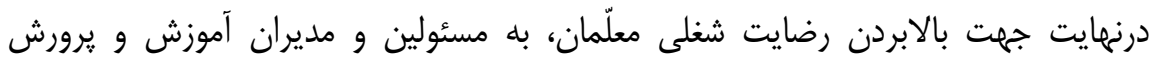

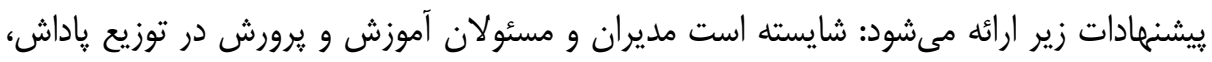


تفويض اختيار، مشاركت و روابط اجتماعى با معلّمان، دقّت نظر داشته باشند و منصفانه عمل كنند؛

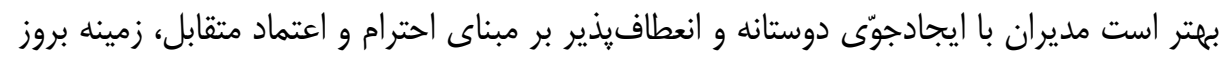

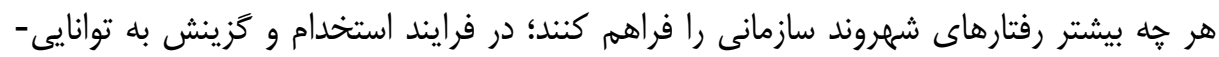

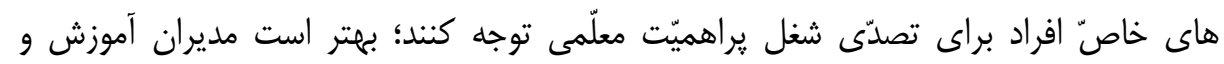

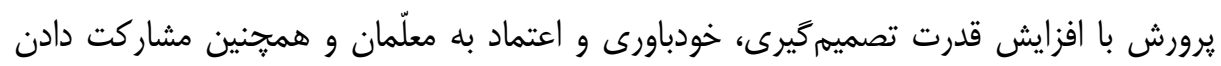

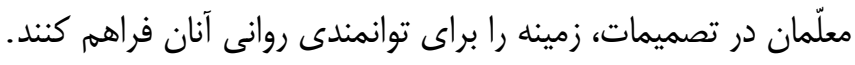

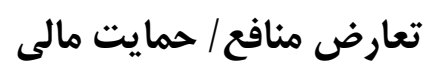

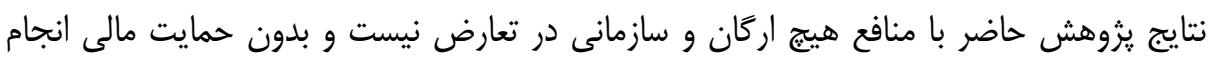
شده است.

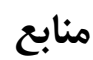

1. Adamy, M. (2018). The Effect of Job Satisfaction and Work Motivation on Organizational Commitment and Organizational Citizenship Behavior in BNI in the Working Area of Bank Indonesia Lhokseumawe. In Proceedings of MICoMS 2017. Emerald Publishing Limited.

2. Aghajani, H. A., Samadi Miarkolaei, H., \& Samadi Miarkolaei, H. (2013). Organizational Citizenship Behavior's Relationship and Staffs' Psychological Empowerment. governmental management. 5(2), 1-18. [in Persian].

3. Ahmad, I., Donia, M. B., Khan, A., \& Waris, M. (2019). Do as I say and do as I do? The mediating role of psychological contract fulfillment in the relationship between ethical leadership and employee extra-role performance. Personnel review.

4. Aldaihani, S. G. (2019). Administrative empowerment among Kuwait University staff and its effect on their job satisfaction. Journal of Applied Research in Higher Education.

5. Amundsen, S., \& Martinsen, Ø. L. (2015). Linking empowering leadership to job satisfaction, work effort, and creativity: The role of self-leadership and psychological empowerment. Journal of Leadership \& Organizational Studies, 22(3), 304-323.

6. Arab, H. R., \& Atan, T. (2018). Organizational justice and work outcomes in the Kurdistan Region of Iraq. Management Decision.

7. Arefin, S., Arif, I., \& Raquib, M. (2015). The mediating role of psychological empowerment in the relationship between high-performance 
work systems and organizational citizenship behavior. European Scientific Journal, 11(2).

8. Bateman, T. S., \& Organ, D. W. (1983). Job satisfaction and the good soldier: The relationship between affect and employee "citizenship". Academy of management Journal, 26(4), 587-595.

9. Belwalkar, S., Vohra, V., \& Pandey, A. (2018). The relationship between workplace spirituality, job satisfaction and organizational citizenship behaviors-an empirical study. Social Responsibility Journal.

10. Bizri, R. (2018). Diversity management and OCB: the connection evidence from the Lebanese banking sector. Equality, Diversity and Inclusion: An International Journal.

11. Bogler, R., \& Somech, A. (2005). Organizational citizenship behavior in school. Journal of educational Administration.

12. Carless, S. A. (2004). Does psychological empowerment mediate the relationship between psychological climate and job satisfaction?. Journal of Business and Psychology, 18(4), 405-425.

13. Chan, S. H. J., \& Lai, H. Y. I. (2017). Understanding the link between communication satisfaction, perceived justice and organizational citizenship behavior. Journal of business research, 70, 214-223.

14. Chiang, C. F., \& Hsieh, T. S. (2012). The impacts of perceived organizational support and psychological empowerment on job performance: The mediating effects of organizational citizenship behavior. International journal of hospitality management, 31(1), 180-190.

15. Clay-Warner, J., Reynolds, J., \& Roman, P. (2005). Organizational justice and job satisfaction: A test of three competing models. Social Justice Research, 18(4), 391-409.

16. Colquitt, J. A., Conlon, D. E., Wesson, M. J., Porter, C. O., \& Ng, K. Y. (2001). Justice at the millennium: a meta-analytic review of 25 years of organizational justice research. Journal of applied psychology, 86(3), 425.

17. Curry, C. D. (2016). Exploring vertical and horizontal dimensions of individualism and collectivism as predictors of organizational citizenship behavior (Doctoral dissertation, Barry University).

18. Dabo, Z., \& Ndan, R. T. (2018). Impact of employee empowerment on organization performance: evidence from quoted bottling companies in kaduna. International Journal of Economics, Business and Management Research, 2(1), 360-369.

19. Dargahi, H., \& Morshedi Tarbati, M. (2017). The Relationship between Organizational Citizenship Behavior with Job Satisfaction and Organizational Commitment of Nurses in Tehran University of Medical 
Sciences General Hospitals. Quarterly Journal of Management Strategies in Health System, 2(3), 234-246. [in Persian].

20. DeConinck, J. B., \& Stilwell, C. D. (2004). Incorporating organizational justice, role states, pay satisfaction and supervisor satisfaction in a model of turnover intentions. Journal of Business Research, 57(3), 225-231.

21. Eidy, H., Faraji, R., Sadeghi, A., \& Nasseri Pelangard, V. (2018). The Role of Organizational Justice in Psychological Empowerment of Sport and Youth Officers of Ilam Province. Human Resource Management in Sport, 5(2), 187-201. [Persian].

22. El-Kot, G., Burke, R. J., \& Fiksenbaum, L. M. (2019). Egyptian women supervisory empowerment behaviors on well-being outcomes. Gender in Management: An International Journal.

23. Fassina, N. E., Jones, D. A., \& Uggerslev, K. L. (2008). Relationship clean-up time: Using meta-analysis and path analysis to clarify relationships among job satisfaction, perceived fairness, and citizenship behaviors. Journal of Management, 34(2), 161-188.

24. Foote, D. A., \& Tang, T. L. P. (2008). Job satisfaction and organizational citizenship behavior (OCB). Management Decision.

25. Franz, C. (2004). A cross-cultural study of employee empowerment and organizational justice (Doctoral dissertation, ProQuest Information \& Learning).

26. Frazier, M. L., \& Fainshmidt, S. (2012). Voice climate, work outcomes, and the mediating role of psychological empowerment: A multilevel examination. Group \& Organization Management, 37(6), 691-715.

27. Ganji, F., \& karimi baghmalek, A. (2018). Investigate, identify and evaluate factors on psychological empowerment and its relationship with organizational citizenship behavior. Frooyesh, 7(7), 219-230. [Persian].

28. Gao, Y., \& He, W. (2017). Corporate social responsibility and employee organizational citizenship behavior. Management Decision.

29. Ghahramani, M., Shams Moorkani, G., \& Seif Panahi, H. (2015). The Study of the Mediating Role of Psychological Empowerment Components in Explaining the Relationship between Organizational Learning Mechanisms and Job Satisfaction of Kurdistan University Personnel. Journal of Management and Planning in Educational Systems, 8(14), 6784. [in Persian].

30. Ghiasi Nadishan, S., Jahani Javanmardi, F., \& Khorsandi taskoh, A. (2017). The relationship between psychological empowerment and creativity among the staff of the Ministry of Communications and 
Information Technology. Innovation in the Humanities, 6(3), 77-96. [in Persian].

31. Gholampour, M., \& Pourshafei, H. (2018). The Role of Organizational Justice in Job Satisfaction with Nursing Burnout Mediation. Journal of Health and Care, 20(1), 7-17. [in Persian].

32. Gilbert, S., Laschinger, H. K., \& Leiter, M. (2010). The mediating effect of burnout on the relationship between structural empowerment and organizational citizenship behaviours. Journal of Nursing Management, 18(3), 339-348.

33. Gupta, V., \& Singh, S. (2013). An empirical study of the dimensionality of organizational justice and its relationship with organizational citizenship behaviour in the Indian context. The International Journal of Human Resource Management, 24(6), 1277-1299.

34. Hao, Y., Hao, J., \& Wang, X. (2016). The relationship between organizational justice and job satisfaction. Journal of Chinese Human Resource Management.

35. Holdsworth, L., \& Cartwright, S. (2003). Empowerment, stress and satisfaction: an exploratory study of a call centre. Leadership \& Organization Development Journal.

36. Hosie, P., Jayashree, P., Tchantchane, A., \& Lee, B. S. (2013). The effect of autonomy, training opportunities, age and salaries on job satisfaction in the South East Asian retail petroleum industry. The International Journal of Human Resource Management, 24(21), 3980-4007.

37. Idris, A., See, D., \& Coughlan, P. (2018). Employee empowerment and job satisfaction in urban Malaysia. Journal of Organizational Change Management.

38. Ioannidou, E., Karagiorgos, T., \& Alexandris, K. (2016). Exploring the relationship of organizational commitment, organizational citizenship behavior, psychological empowerment and job satisfaction with LeaderMember Exchange of section leaders and team leaders in summer children's camps in Greece. International Journal of Sport Management, Recreation and Tourism, 22, 63-80.

39. Irving, P. G., Coleman, D. F., \& Bobocel, D. R. (2005). The Moderating Effect of Negative Affectivity in the Procedural Justice-Job Satisfaction Relation. Canadian Journal of Behavioural Science/Revue canadienne des sciences du comportement, 37(1), 20.

40. Ivancevich, J. M., \& Matteson, M. T. (2005). The measurement of experienced evidence. Journal of Occupational Behaviour, 10(2), 99-113. 
41. Jamshidian, M. A. (2017). The Impact of Empowerment on Organizational Commitment and Job Satisfaction in the General Department of Roads and Urban Development of Markazi Province. Journal of Science and Engineering Elite. 2(5), 1-11. [in Persian].

42. Jiang, J. Y., Sun, L. Y., \& Law, K. S. (2011). Job satisfaction and organization structure as moderators of the effects of empowerment on organizational citizenship behavior: A self-consistency and social exchange perspective. International Journal of Management, 28(3), 675.

43. Khalifa Sultani, H., Saedi, A., \& Etemadian, S. (2017). The Impact of Transformational Leadership on Employee Psychological Empowerment in Order to Develop Capabilities and Entrepreneurial Activities in Organization. Quarterly Journal of Organizational Behavior Studies, 6(1), 121-145. [in Persian].

44. Kordnaij, A., Bakhshi Zadeh, A. R., \& Fatah Elahi, M. (2015). The Effect of Psychological Empowerment of Staff on Structural Empowerment. Organizational Behavior Studies, 4(14), 97-119. [in Persian].

45. Kundu, S. C., Mor, A., Bansal, J., \& Kumar, S. (2019). Diversity-focused HR practices and perceived firm performance: mediating role of procedural justice. Journal of Asia Business Studies.

46. Lamm, E., Tosti-Kharas, J., \& King, C. E. (2015). Empowering employee sustainability: Perceived organizational support toward the environment. Journal of Business Ethics, 128(1), 207-220.

47. Lee, K. E., Kim, J. H., \& Kim, M. J. (2016). Influence of perceived organizational justice on empowerment, organizational commitment and turnover intention in the hospital nurses. Indian Journal of Science and Technology, 9(20), 94702.

48. Li, M., Liu, W., Han, Y., \& Zhang, P. (2016). Linking empowering leadership and change-oriented organizational citizenship behavior. Journal of Organizational Change Management.

49. Madera, J. M., Dawson, M., \& Guchait, P. (2016). Psychological diversity climate: justice, racioethnic minority status and job satisfaction. International Journal of Contemporary Hospitality Management.

50. Meynhardt, T., Brieger, S. A., \& Hermann, C. (2020). Organizational public value and employee life satisfaction: The mediating roles of work engagement and organizational citizenship behavior. The International Journal of Human Resource Management, 31(12), 1560-1593.

51. Mirmoini, S. Y., Jalali Farahani, M., \& Alidoust, E. (2016). Designing of organizational citizenship behavior of tehran city perdition model for 
physical education from job satisfaction,organizational commitment and organizational justice. Journal of Organizational Behavior Management Studies in Sport, 3(4), 111-123. [in Persian].

52. Mohammadkhani, K., Mohammad Davoodi, A. H., \& Razakparast, A. (2013). Relationship between Psychological Empowerment, Happiness with Organizational Citizenship Behavior among Islamic Azad University Staff (Tehran Science \& Research Branch. Urban Management Study, 5(13), 70-81. [in Persian].

53. Mohseni, S., \& Mirgol, A. (2019). Predicting Job Satisfaction Based on Organizational Justice and Quality of Life in Teachers. New Research Approaches to Management and Accounting, 9(3), 1-7. [in Persian].

54. Moradi, E., Safania, A. M., \& Poursoltani Zarandi, H. (2019). The causal relationship between dimensions of organizational silence with organizational citizenship behavior in staff of youth and sport organizations of Khuzestan province: Mediating role of organizational justice. Applied Research in Sport Management, 7(4), 99-108. [in Persian].

55. Movahhed, A., \& Abbasi, Z. (2019). The Role of Psychological Empowerment in the Prediction of Psychological Well - Being in Health Care Workers ran. Health Management, 10(1), 53-65. [in Persian].

56. Munawir, M., Raharjo, K., Djalil, M. A., Syahputra, H., Muslim, B., \& Adam, M. (2019). Dimensions of identity strength and organizational citizenship behavior (OCB) in establishing good university governance and performance of religious ideology-based higher educations. Journal of Applied Research in Higher Education.

57. Muqadas, F., Rehman, C. A., \& Aslam, U. (2017). Organizational justice and employee's job dissatisfaction: a moderating role of psychological empowerment. Pakistan Business Review, 18(4), 848-864.

58. Naderi, F., \& Saffarzadeh, S. (2014). The Relationship between Organizational Justice, Organizational Health, Job Conditions and Organizational Culture with Psychological Ability and Organizational Research. Cognition and Research in Applied Psychology, 15(2), 56-68. [in Persian].

59. Nadi, M. A., \& Esmaeili Harandi, F. (2017). Structural Modeling of Organizational Justice, Job Satisfaction, Organizational Commitment with Deviant Behavior Among High School Teachers in Isfahan. Quarterly Journal of A New Approach to Educational Management, 7(28), 59-83. [in Persian].

60. Nadi, M. A., Moshfeghi, N., \& Mir Lohi, H. (2018). Explain the moderating role of attachment to change in structural relations of ethical 
leadership, job satisfaction and organizational citizenship behavior and organizational performance. Educational Management Innovations, 13(1), 39-55. [in Persian].

61. Nadiri, H., \& Tanova, C. (2010). An investigation of the role of justice in turnover intentions, job satisfaction, and organizational citizenship behavior in hospitality industry. International journal of hospitality management, 29(1), 33-41.

62. Nazari, R., \& Rafei, F. (2018). Improving Organizational Commitment of Staff of Sports Media through Intermediacy Role of Organizational Justice and Job Satisfaction. Communication Management in Sports Media, 5(3), 39-48. [in Persian].

63. Nazir, S., Shafi, A., Atif, M. M., Qun, W., \& Abdullah, S. M. (2019). How organization justice and perceived organizational support facilitate employees' innovative behavior at work. Employee Relations: The International Journal.

64. Newman, A., Schwarz, G., Cooper, B., \& Sendjaya, S. (2017). How servant leadership influences organizational citizenship behavior: The roles of LMX, empowerment, and proactive personality. Journal of Business Ethics, 145(1), 49-62.

65. Niehoff, B. P., \& Moorman, R. H. (1993). Justice as a mediator of the relationship between methods of monitoring and organizational citizenship behavior. Academy of Management Journal, 36(3): 527-556.

66. Oh, S. Y. (2019). Effects of organizational learning on performance: the moderating roles of trust in leaders and organizational justice. Journal of Knowledge Management.

67. Ölçer, F., \& Florescu, M. (2015). Mediating effect of job satisfaction in the relationship between psychological empowerment and job performance. Theoretical and Applied Economics, 22(3), 111-136.

68. Organ, D. W. (1997). Organizational citizenship behavior: It's construct clean-up time. Human performance, 10(2), 85-97.

69. PahlavanSadegh, A., Abdollahi, B. (2015). Structural Model of Relationship between Psychological Empowerment and Job Satisfaction, and Mediating Role of Self-Efficacy and Self-Regulation (Case Study: University of Kharazmi). Journal of Management and Planning In Educational System, 8(1), 85-112. [in Persian].

70. Paillé, P. (2011). Stressful work, citizenship behaviour and intention to leave the organization in a high turnover environment: examining the mediating role of job satisfaction. Journal of Management Research, 3(1), $1-14$. 
71. Paul, H., Bamel, U., Ashta, A., \& Stokes, P. (2019). Examining an integrative model of resilience, subjective well-being and commitment as predictors of organizational citizenship behaviours. International Journal of Organizational Analysis.

72. Pelit, E., Öztürk, Y., \& Arslantürk, Y. (2011). The effects of employee empowerment on employee job satisfaction. International Journal of Contemporary Hospitality Management.

73. Podsakoff, P. M., MacKenzie, S. B., \& Hui, C. (1993). Organizational citizenship behaviors and managerial evaluations of employee performance: A review and suggestions for future research. Research in personnel and human resources management.

74. Podsakoff, P., MacKenzie, S., Moorman, R., \& Fetter, R. (1990). Transformational leader behaviors and their effects on followers' trust in leader, satisfaction, and organizational citizenship behavior. Leadership Quarterly, 1(2), 107-142.

75. Pourseltani Mirzaei, F., \& Zareian, H. (2012). The relationship between perception of justice and job satisfaction in sport science research center of Ministry of science, research and technology's staffs. Contemporary Research in Sport Management, 1(1), 59-70. [in Persian].

76. Rahimi, G., \& Mazaheri Rad, H. (2017). A Descriptive Study of the Impact of Psychological Empowerment on Silence Among Organizational Staff. New Research Approaches to Management and Accounting, 1(1), 35-54. [in Persian].

77. Rahman Sarsat, H., \& Janidi Jafari, M. (2018). The Effect of Organizational Justice on Organizational Citizenship Behavior by Mediating Job Commitment in Project Management. Studies of management, improvement and transformation, 27(87), 127-146. [in Persian].

78. Safari, S., Omidi, A., Sajjadi, N., \& Khabiri, M. (2016). The Relationship of Psychological Empowerment, Organizational Commitment and Organizational Citizenship Behavior in Physical Education Teachers of Iran High Schools. Journal of Sport Management, 8(1), 1-23. [in Persian].

79. Safarzadeh, S., Naderi, F., Asgari, P., Anayati, M., \& Heydari, A. (2017). The Relationship of Organization justice, Organizational Health, Job Engagement and Climate With Psychological Empowerment a Organizational Citizenship Behavior. Knowledge and Research in Applied Psychology, 15(56), 56-68. [in Persian].

80. Safi, M. H., Mohammadi, F., \& Arshi, S. (2015). The Relationship between Administrative Justice and Perceived Organizations with Work 
Organization with Job Satisfaction in North Tehran Health Care Workers. Journal of Community Health, 2(3), 172-181. [in Persian].

81. Salajegah, S., Sheikhpour, M., \& Nazeri, M. (2018). A Model for Identifying the Relationship between Intellectual Capital and Psychological Empowerment of the Staff of Islamic Azad University of Kerman Branch. Educational Management Innovations, 14(1), 101-114. [in Persian].

82. Salimi, J., \& Abdi, A. (2018). On the relationship between psychological empowerment and job satisfaction of teachers: Investigating the mediator role of organizational citizenship behavior. School Psychology, 6(4), 7098. [in Persian].

83. Seibert, S. E., Wang, G., \& Courtright, S. H. (2011). Antecedents and consequences of psychological and team empowerment in organizations: A meta-analytic review. Journal of applied psychology, 96(5), 981.

84. Singh, S. K., \& Singh, A. P. (2019). Interplay of organizational justice, psychological empowerment, organizational citizenship behavior, and job satisfaction in the context of circular economy. Management Decision.

85. Singhry, H. B. (2018). Perceptions of leader transformational justice and job satisfaction in public organizations. International Journal of Public Leadership.

86. Skarlicki, D. P., \& Folger, R. (2003). HRMR special issue: Fairness and human resources management. Human Resource Management Review, 1(13), 1-5.

87. Somech, A., \& Ron, I. (2007). Promoting organizational citizenship behavior in schools: The impact of individual and organizational characteristics. Educational administration quarterly, 43(1), 38-66.

88. Spreitzer, G. M. (1995). Psychological empowerment in the workplace: Dimensions, measurement, and validation. Academy of management Journal, 38(5), 1442-1465.

89. Sudin, S. (2011). Fairness of and satisfaction with performance appraisal process. Journal of Global Management, 2(1), 66-83.

90. Suifan, T. S., Diab, H., \& Abdallah, A. B. (2017). Does organizational justice affect turnover-intention in a developing country? The mediating role of job satisfaction and organizational commitment. Journal of Management Development.

91. Takeuchi, R., Bolino, M. C., \& Lin, C. C. (2015). Too many motives? The interactive effects of multiple motives on organizational citizenship behavior. Journal of Applied Psychology, 100(4), 1239. 
92. Top, M., Akdere, M., \& Tarcan, M. (2015). Examining transformational leadership, job satisfaction, organizational commitment and organizational trust in Turkish hospitals: public servants versus private sector employees. The International Journal of Human Resource Management, 26(9), 1259-1282.

93. Ulutas, G., Ustubioglu, B., Ulutas, M., \& Nabiyev, V. V. (2018). Frame duplication detection based on bow model. Multimedia Systems, 24(5), 549-567.

94. Vazifeh, Z., Rezghi Rostami, S, \& Pakdel, H. (2019). The Effect of Empowering Employees on Organizational Innovation with the Mediating Role of Job Satisfaction (Case Study: Islamic Azad University, South Tehran Branch). New Research Approaches to Management and Accounting, 9(3), 113-122. [in Persian].

95. Wang, G., \& Lee, P. D. (2009). Psychological empowerment and job satisfaction: An analysis of interactive effects. Group \& organization management, 34(3), 271-296.

96. Wong, Y. T., Ngo, H. Y., \& Wong, C. S. (2006). Perceived organizational justice, trust, and OCB: A study of Chinese workers in joint ventures and state-owned enterprises. Journal of World Business, 41(4), 344-355.

97. Zahednezhad, H., Manoochehti, H., Zaghari Tafreshi, M., Farokhnezhad Afshar, P., \& Ghanei Gheshlagh, R. (2015). The Relationship between Organizational Justice and Nursing Psychological Empowerment. Iranian Journal of Nursing, 28(93), 78-86. [in Persian].

98. Zeinabadi, H. (2011). Transformational leadership and organizational citizenship behavior in school: Retesting and changing a tested model in industry. Governmental Management, 3(7):63-80. [in Persian].

99. Zhang, X., \& Bartol, K. M. (2010). Linking empowering leadership and employee creativity: The influence of psychological empowerment, intrinsic motivation, and creative process engagement. Academy of management journal, 53(1), 107-128. 